\title{
Mitochondrial Redox Opto-Lipidomics Reveals Mono-Oxygenated Cardiolipins as Pro-Apoptotic Death Signals
}

Gaowei Mao ${ }^{1,2, \dagger}$, Feng Qu ${ }^{1,2, \dagger}$, Claudette M. St. Croix ${ }^{2,3}$, Yulia Y. Tyurina ${ }^{1,2}$, Joan Planas-Iglesias ${ }^{4}$, Jianfei Jiang ${ }^{1,2}$, Zhentai Huang ${ }^{1,2}$, Andrew A. Amoscato ${ }^{1,2}$, Vladimir A. Tyurin ${ }^{1,2}$, Alexandr A. Kapralov ${ }^{1,2}$, Amin Cheikhi $^{1,2}$, John Maguire ${ }^{1,2}$, Judith Klein-Seetharaman ${ }^{4}$, Hülya Bayır ${ }^{1,2,5}$, and Valerian E. Kagan ${ }^{1,2, *}$

${ }^{1}$ Center for Free Radical and Antioxidant Health, ${ }^{2}$ Departments of Environmental and Occupational Health, ${ }^{3}$ Center for Biological Imaging, University of Pittsburgh,

Pittsburgh, PA, 4Division of Metabolic and Vascular Health, Medical School, University of Warwick, Coventry, UK, ${ }^{5}$ Department of Critical Care Medicine, Safar Center for Resuscitation Research, University of Pittsburgh, Pittsburgh, PA 
Supporting information table S1. Lipid composition in all groups. Data was presented as mean \pm standard deviation, $\mathrm{pmol} / \mathrm{nmol} \mathrm{PL}$, $n=3$.

\begin{tabular}{|c|c|c|c|c|c|c|c|c|c|c|c|c|c|c|c|c|c|c|}
\hline \multirow{2}{*}{$\begin{array}{l}\text { Lipids } \\
\mathrm{CL}(16: 1 / 16: 1 / 20: 4 / 18: 2)\end{array}$} & \multicolumn{3}{|c|}{ Control } & \multicolumn{3}{|c|}{ NAO+Light $0.5 \mathrm{~h}$} & \multicolumn{3}{|c|}{ NAO+Light $6 \mathrm{~h}$} & \multicolumn{3}{|c|}{ NAO+Light $48 \mathrm{~h}$} & \multicolumn{3}{|c|}{$\mathrm{NAO}+$ Light+FCCP $0.5 \mathrm{~h}$} & \multicolumn{3}{|c|}{ NAO+Light+FCCP 48h } \\
\hline & $4.3 \mathrm{E}-02$ & \pm & $9.5 \mathrm{E}-04$ & 5.3E-F02 & \pm & $3.3 \mathrm{E}-03$ & $6.1 \mathrm{E}-02$ & \pm & $1.9 \mathrm{E}-03$ & $5.0 \mathrm{E}-02$ & \pm & $6.8 \mathrm{E}-04$ & $4.3 \mathrm{E}-02$ & \pm & $2.1 \mathrm{E}-03$ & $5.6 \mathrm{E}-02$ & \pm & $3.7 \mathrm{E}-03$ \\
\hline $\mathrm{CL}(16: 1 / 18: 1 / 18: 2 / 18: 1)$ & $1.5 \mathrm{E}+00$ & \pm & $3.3 \mathrm{E}-02$ & $2.0 \mathrm{E}+00$ & \pm & $5.7 \mathrm{E}-02$ & $2.2 \mathrm{E}+00$ & \pm & $1.8 \mathrm{E}-01$ & $1.2 \mathrm{E}+00$ & \pm & $4.5 \mathrm{E}-02$ & $1.5 \mathrm{E}+00$ & \pm & $9.5 \mathrm{E}-02$ & $1.5 \mathrm{E}+00$ & \pm & $4.4 \mathrm{E}-02$ \\
\hline $\mathrm{CL}(16: 1 / 18: 2 / 18: 2 / 18: 1)$ & $1.0 \mathrm{E}+00$ & \pm & $5.3 \mathrm{E}-02$ & $1.2 \mathrm{E}+00$ & \pm & $3.6 \mathrm{E}-02$ & $1.2 \mathrm{E}+00$ & \pm & $2.2 \mathrm{E}-02$ & 8.3E-01 & \pm & 2.4E-02 & $1.0 \mathrm{E}+00$ & \pm & $2.8 \mathrm{E}-02$ & $9.9 \mathrm{E}-01$ & \pm & $2.2 \mathrm{E}-02$ \\
\hline $\mathrm{CL}(16: 1 / 18: 2 / 18: 2 / 18: 2)$ & $2.7 \mathrm{E}-01$ & \pm & $1.5 \mathrm{E}-02$ & $3.4 \mathrm{E}-01$ & \pm & $1.7 \mathrm{E}-03$ & $3.3 \mathrm{E}-01$ & \pm & $2.1 \mathrm{E}-02$ & $1.9 \mathrm{E}-01$ & \pm & $1.3 \mathrm{E}-02$ & $2.8 \mathrm{E}-01$ & \pm & $6.5 \mathrm{E}-03$ & $2.6 \mathrm{E}-01$ & \pm & $1.8 \mathrm{E}-02$ \\
\hline $\operatorname{CL}(18: 0 / 18: 1 / 18: 2 / 18: 1)$ & $6.5 \mathrm{E}-01$ & \pm & $2.4 \mathrm{E}-02$ & $8.4 \mathrm{E}-01$ & \pm & $1.8 \mathrm{E}-02$ & $7.9 \mathrm{E}-01$ & \pm & $3.1 \mathrm{E}-02$ & $5.6 \mathrm{E}-01$ & \pm & $1.8 \mathrm{E}-02$ & 6.6E-01 & \pm & $3.9 \mathrm{E}-02$ & $6.6 \mathrm{E}-01$ & \pm & $9.2 \mathrm{E}-02$ \\
\hline $\mathrm{CL}(18: 0 / 18: 1 / 18: 2 / 18: 1)-\mathrm{OH}$ & N.D. & & & 1.6E-03 & \pm & $3.3 \mathrm{E}-04$ & 4.4E-04 & \pm & $1.2 \mathrm{E}-04$ & $5.5 \mathrm{E}-04$ & \pm & $5.0 \mathrm{E}-04$ & 4.9E-05 & \pm & 8.4E-05 & $9.1 \mathrm{E}-05$ & \pm & $1.6 \mathrm{E}-04$ \\
\hline $\mathrm{CL}(18: 1 / 18: 1 / 18: 2 / 20: 1)$ & $6.6 \mathrm{E}-02$ & \pm & $5.8 \mathrm{E}-03$ & $1.4 \mathrm{E}-01$ & \pm & $4.8 \mathrm{E}-02$ & $9.4 \mathrm{E}-02$ & \pm & $5.7 \mathrm{E}-03$ & $6.8 \mathrm{E}-02$ & \pm & $9.9 \mathrm{E}-03$ & $7.5 \mathrm{E}-02$ & \pm & $5.0 \mathrm{E}-03$ & $6.6 \mathrm{E}-02$ & \pm & $6.8 \mathrm{E}-03$ \\
\hline $\mathrm{CL}(18: 1 / 18: 2 / 16: 0 / 16: 1)$ & 4.7E-01 & \pm & $1.3 \mathrm{E}-02$ & $5.6 \mathrm{E}-01$ & \pm & $2.7 \mathrm{E}-02$ & $5.6 \mathrm{E}-01$ & \pm & $3.3 \mathrm{E}-02$ & 4.5E- 01 & \pm & $3.4 \mathrm{E}-02$ & 4.3E-01 & \pm & $2.6 \mathrm{E}-02$ & 4.6E-01 & \pm & $5.3 \mathrm{E}-03$ \\
\hline $\mathrm{CL}(18: 1 / 18: 2 / 18: 1 / 18: 1)$ & $9.1 \mathrm{E}-01$ & \pm & $4.5 \mathrm{E}-02$ & $1.1 \mathrm{E}+00$ & \pm & $8.2 \mathrm{E}-02$ & $1.1 \mathrm{E}+00$ & \pm & $6.8 \mathrm{E}-02$ & 8.1E-01 & \pm & 4.1E-02 & $9.0 \mathrm{E}-01$ & \pm & $5.0 \mathrm{E}-02$ & $1.0 \mathrm{E}+00$ & \pm & $5.4 \mathrm{E}-02$ \\
\hline $\mathrm{CL}(18: 1 / 18: 1 / 18: 1 / 18: 2-\mathrm{OH})$ & 4.3E-05 & \pm & 7.4E-05 & $1.9 \mathrm{E}-04$ & \pm & 3.0E-05 & $2.1 \mathrm{E}-04$ & \pm & 4.6E-05 & $3.4 \mathrm{E}-04$ & \pm & $2.9 \mathrm{E}-04$ & 4.2E-04 & \pm & $4.8 \mathrm{E}-04$ & 4.4E-04 & \pm & $2.5 \mathrm{E}-04$ \\
\hline CL(18:1/18:2/18:1/18:2) & $2.5 \mathrm{E}+00$ & \pm & 1.5E-01 & $3.1 \mathrm{E}+00$ & \pm & $1.6 \mathrm{E}-02$ & $2.9 \mathrm{E}+00$ & \pm & $3.5 \mathrm{E}-01$ & $2.2 \mathrm{E}+00$ & \pm & $1.5 \mathrm{E}-01$ & $2.3 E+00$ & \pm & $1.3 \mathrm{E}-01$ & $2.6 \mathrm{E}+00$ & \pm & $1.7 \mathrm{E}-01$ \\
\hline $\mathrm{CL}(18: 1 / 18: 2 / 18: 1 / 18: 2-\mathrm{OH})$ & $4.8 \mathrm{E}-04$ & \pm & $1.3 \mathrm{E}-04$ & 2.4E-02 & \pm & $2.8 \mathrm{E}-03$ & $1.1 \mathrm{E}-02$ & \pm & $1.4 \mathrm{E}-03$ & N.D. & \pm & N.D. & $9.4 \mathrm{E}-04$ & \pm & $9.0 \mathrm{E}-04$ & $2.8 \mathrm{E}-04$ & \pm & $2.7 \mathrm{E}-04$ \\
\hline $\mathrm{CL}(18: 1 / 18: 2 / 18: 2 / 18: 2)$ & $1.6 \mathrm{E}+00$ & \pm & $1.2 \mathrm{E}-01$ & $1.9 \mathrm{E}+00$ & \pm & $4.8 \mathrm{E}-02$ & $1.8 \mathrm{E}+00$ & \pm & $5.0 \mathrm{E}-02$ & $1.3 \mathrm{E}+00$ & \pm & $9.7 \mathrm{E}-02$ & $1.6 \mathrm{E}+00$ & \pm & $7.2 \mathrm{E}-02$ & $1.4 \mathrm{E}+00$ & \pm & $7.3 \mathrm{E}-02$ \\
\hline $\mathrm{CL}(18: 1 / 18: 2 / 18: 2 / 18: 2-\mathrm{OH})$ & N.D. & & & $5.0 \mathrm{E}-04$ & \pm & $5.1 \mathrm{E}-04$ & 4.0E-04 & \pm & $7.9 \mathrm{E}-05$ & $1.4 \mathrm{E}-03$ & \pm & $6.4 \mathrm{E}-04$ & $1.3 \mathrm{E}-04$ & \pm & $1.3 \mathrm{E}-04$ & $2.6 \mathrm{E}-04$ & \pm & 2.5E-04 \\
\hline $\operatorname{CL}(16: 1 / 18: 2 / 16: 1 / 16: 1)$ & $3.9 \mathrm{E}-02$ & \pm & 3.7E-03 & $4.5 \mathrm{E}-02$ & \pm & $7.2 \mathrm{E}-04$ & $4.2 \mathrm{E}-02$ & \pm & $4.2 \mathrm{E}-03$ & $2.0 \mathrm{E}-02$ & \pm & $5.1 \mathrm{E}-04$ & $3.4 \mathrm{E}-02$ & \pm & $2.4 \mathrm{E}-03$ & $4.5 \mathrm{E}-02$ & \pm & $2.2 \mathrm{E}-03$ \\
\hline $\mathrm{CL}(16: 1 / 18: 2 / 18: 2 / 16: 1)$ & $8.1 \mathrm{E}-03$ & \pm & $2.0 \mathrm{E}-03$ & 1.1E-02 & \pm & $1.2 \mathrm{E}-03$ & $1.4 \mathrm{E}-02$ & \pm & $2.3 \mathrm{E}-03$ & $7.9 \mathrm{E}-03$ & \pm & 1.7E-03 & $9.7 \mathrm{E}-03$ & \pm & $1.9 \mathrm{E}-03$ & $1.4 \mathrm{E}-02$ & \pm & $2.2 \mathrm{E}-03$ \\
\hline $\operatorname{CL}(18: 1 / 18: 2 / 16: 1 / 14: 0)$ & $9.7 \mathrm{E}-02$ & \pm & $4.1 \mathrm{E}-03$ & $1.2 \mathrm{E}-01$ & \pm & $5.7 \mathrm{E}-03$ & $1.3 \mathrm{E}-01$ & \pm & $6.2 \mathrm{E}-03$ & $7.9 \mathrm{E}-02$ & \pm & 7.4E-03 & 1.1E-01 & \pm & $8.3 \mathrm{E}-03$ & $1.2 \mathrm{E}-01$ & \pm & $2.0 \mathrm{E}-02$ \\
\hline $\mathrm{CL}(18: 1 / 18: 2 / 18: 0 / 20: 3)$ & $2.4 \mathrm{E}-01$ & \pm & $5.8 \mathrm{E}-03$ & 3.3E-01 & \pm & $2.3 \mathrm{E}-02$ & $2.9 \mathrm{E}-01$ & \pm & $1.2 \mathrm{E}-02$ & 2.6E-01 & \pm & $6.7 \mathrm{E}-02$ & $2.2 \mathrm{E}-01$ & \pm & $2.0 \mathrm{E}-02$ & 2.1E-01 & \pm & $9.3 \mathrm{E}-03$ \\
\hline $\mathrm{CL}(18: 1 / 18: 2 / 18: 0 / 20: 3)-\mathrm{OH}$ & $8.2 \mathrm{E}-05$ & \pm & $1.4 \mathrm{E}-04$ & $2.9 \mathrm{E}-04$ & \pm & 4.5E-05 & $2.4 \mathrm{E}-04$ & \pm & $6.1 \mathrm{E}-05$ & N.D. & \pm & N.D. & 1.6E-04 & \pm & $2.7 \mathrm{E}-04$ & $2.1 \mathrm{E}-04$ & \pm & $1.8 \mathrm{E}-04$ \\
\hline $\mathrm{CL}(18: 1 / 18: 2 / 18: 1 / 20: 3)$ & $6.0 \mathrm{E}-01$ & \pm & $6.2 \mathrm{E}-02$ & $8.7 \mathrm{E}-01$ & \pm & $1.8 \mathrm{E}-02$ & 8.3E-01 & \pm & $5.7 \mathrm{E}-02$ & 4.7E-01 & \pm & $1.3 \mathrm{E}-02$ & $6.8 \mathrm{E}-01$ & \pm & $4.0 \mathrm{E}-02$ & $6.1 \mathrm{E}-01$ & \pm & $8.7 \mathrm{E}-03$ \\
\hline $\mathrm{CL}(18: 1 / 18: 2 / 18: 1 / 20: 3)-\mathrm{OH}$ & N.D. & & & $1.6 \mathrm{E}-03$ & \pm & 2.6E-04 & $2.4 \mathrm{E}-04$ & \pm & $2.8 \mathrm{E}-04$ & $2.0 \mathrm{E}-04$ & \pm & $3.5 \mathrm{E}-04$ & $1.6 \mathrm{E}-04$ & \pm & $3.8 \mathrm{E}-05$ & N.D. & \pm & N.D. \\
\hline $\mathrm{CL}(18: 1 / 18: 2 / 18: 2 / 20: 3)$ & $6.8 \mathrm{E}-01$ & \pm & $2.5 \mathrm{E}-02$ & $8.8 \mathrm{E}-01$ & \pm & $5.6 \mathrm{E}-02$ & 8.3E-01 & \pm & $1.3 \mathrm{E}-02$ & 4.6E-01 & \pm & $2.0 \mathrm{E}-02$ & 7.5E-01 & \pm & $4.5 \mathrm{E}-02$ & $6.3 \mathrm{E}-01$ & \pm & $4.0 \mathrm{E}-02$ \\
\hline $\mathrm{CL}(18: 1 / 18: 2 / 18: 2 / 20: 3)-\mathrm{OH}$ & N.D. & & & $5.3 \mathrm{E}-03$ & \pm & $1.3 \mathrm{E}-03$ & $1.5 \mathrm{E}-03$ & \pm & $1.2 \mathrm{E}-04$ & $1.8 \mathrm{E}-04$ & \pm & $3.0 \mathrm{E}-04$ & 1.7E-04 & \pm & $1.5 \mathrm{E}-04$ & N.D. & \pm & N.D. \\
\hline $\mathrm{CL}(18: 1 / 18: 2 / 18: 2 / 20: 4)$ & $2.2 \mathrm{E}-01$ & \pm & $1.9 \mathrm{E}-02$ & $2.4 \mathrm{E}-01$ & \pm & $1.6 \mathrm{E}-02$ & $2.8 \mathrm{E}-01$ & \pm & 1.1E-02 & $2.6 \mathrm{E}-01$ & \pm & 1.1E-02 & 2.1E-01 & \pm & $2.1 \mathrm{E}-02$ & $2.9 \mathrm{E}-01$ & \pm & $2.1 \mathrm{E}-02$ \\
\hline $\mathrm{CL}(18: 1 / 18: 2 / 18: 2 / 20: 4)-\mathrm{OH}$ & N.D. & & & 4.4E-03 & \pm & $9.1 \mathrm{E}-04$ & $9.9 \mathrm{E}-04$ & \pm & $5.7 \mathrm{E}-04$ & N.D. & \pm & N.D. & N.D. & \pm & N.D. & N.D. & \pm & N.D. \\
\hline $\mathrm{CL}(18: 1 / 18: 2 / 18: 2 / 20: 4)-\mathrm{OOH}$ & $1.9 \mathrm{E}-04$ & \pm & $1.9 \mathrm{E}-04$ & $2.0 \mathrm{E}-04$ & \pm & $6.0 \mathrm{E}-06$ & $5.8 \mathrm{E}-04$ & \pm & $1.2 \mathrm{E}-04$ & 4.1E-04 & \pm & 3.6E-04 & $2.2 \mathrm{E}-04$ & \pm & $2.6 \mathrm{E}-04$ & $1.2 \mathrm{E}-04$ & \pm & $2.1 \mathrm{E}-04$ \\
\hline $\mathrm{CL}(18: 1 / 18: 2 / 18: 2 / 22: 4)$ & $1.8 \mathrm{E}-01$ & \pm & $2.8 \mathrm{E}-03$ & $2.4 \mathrm{E}-01$ & \pm & $2.3 \mathrm{E}-02$ & $2.3 \mathrm{E}-01$ & \pm & $1.1 \mathrm{E}-03$ & 1.3E-01 & \pm & 4.3E-03 & $1.9 \mathrm{E}-01$ & \pm & $3.3 \mathrm{E}-03$ & $1.7 \mathrm{E}-01$ & \pm & $1.4 \mathrm{E}-02$ \\
\hline $\mathrm{CL}(18: 1 / 18: 2 / 18: 2 / 22: 4)-\mathrm{OOH}$ & $6.1 \mathrm{E}-05$ & \pm & $1.1 \mathrm{E}-04$ & 2.2E- 04 & \pm & $1.4 \mathrm{E}-04$ & $2.2 \mathrm{E}-04$ & \pm & 4.4E-05 & $1.9 \mathrm{E}-04$ & \pm & $3.2 \mathrm{E}-04$ & 5.4E-05 & \pm & $9.3 \mathrm{E}-05$ & $5.5 \mathrm{E}-05$ & \pm & $9.5 \mathrm{E}-05$ \\
\hline CL(18:2/18:2/18:2/18:2) & $8.1 \mathrm{E}-01$ & \pm & 4.0E-02 & $1.1 \mathrm{E}+00$ & \pm & $5.5 \mathrm{E}-02$ & $1.0 \mathrm{E}+00$ & \pm & $9.2 \mathrm{E}-02$ & $7.0 \mathrm{E}-01$ & \pm & 4.1E-02 & $7.9 \mathrm{E}-01$ & \pm & $3.0 \mathrm{E}-02$ & $8.1 \mathrm{E}-01$ & \pm & 4.7E-02 \\
\hline $\mathrm{CL}(18: 2 / 18: 2 / 18: 2 / 20: 4)$ & 1.6E-01 & \pm & $1.2 \mathrm{E}-02$ & 2.2E-01 & \pm & $2.7 \mathrm{E}-02$ & $2.4 \mathrm{E}-01$ & \pm & $2.6 \mathrm{E}-02$ & $1.9 \mathrm{E}-01$ & \pm & 3.6E-03 & $1.8 \mathrm{E}-01$ & \pm & $1.9 \mathrm{E}-02$ & $2.0 \mathrm{E}-01$ & \pm & $6.7 \mathrm{E}-03$ \\
\hline $\mathrm{CL}(18: 2 / 18: 2 / 18: 2 / 20: 4)-\mathrm{O}$ & $6.3 \mathrm{E}-04$ & \pm & $3.1 \mathrm{E}-04$ & $1.3 \mathrm{E}-03$ & \pm & $2.1 \mathrm{E}-04$ & $1.8 \mathrm{E}-03$ & \pm & 7.3E-04 & 1.6E-04 & \pm & $2.8 \mathrm{E}-04$ & $1.5 \mathrm{E}-03$ & \pm & $1.7 \mathrm{E}-04$ & $1.5 \mathrm{E}-03$ & \pm & $1.1 \mathrm{E}-03$ \\
\hline $\mathrm{CL}(18: 2 / 20: 3 / 18: 2 / 20: 4)$ & $6.0 \mathrm{E}-02$ & \pm & $1.2 \mathrm{E}-02$ & $5.4 \mathrm{E}-02$ & \pm & $9.4 \mathrm{E}-03$ & $6.5 \mathrm{E}-02$ & \pm & $2.2 \mathrm{E}-03$ & $4.6 \mathrm{E}-02$ & \pm & $6.3 \mathrm{E}-03$ & 4.5E-02 & \pm & $1.1 \mathrm{E}-02$ & $6.2 \mathrm{E}-02$ & \pm & $9.7 \mathrm{E}-03$ \\
\hline $\mathrm{CL}(18: 2 / 20: 3 / 18: 2 / 20: 4)-\mathrm{OOH}$ & $4.0 \mathrm{E}-03$ & \pm & $6.2 \mathrm{E}-04$ & $5.3 \mathrm{E}-03$ & \pm & $1.9 \mathrm{E}-03$ & $5.6 \mathrm{E}-03$ & \pm & $2.5 \mathrm{E}-03$ & $9.4 \mathrm{E}-04$ & \pm & $9.5 \mathrm{E}-04$ & 4.3E-03 & \pm & $9.6 \mathrm{E}-04$ & $6.4 \mathrm{E}-03$ & \pm & $3.0 \mathrm{E}-03$ \\
\hline
\end{tabular}




\begin{tabular}{|c|c|c|c|c|c|c|c|c|c|c|c|c|c|c|c|c|c|c|}
\hline \multirow{2}{*}{$\begin{array}{l}\text { Lipids } \\
\mathrm{CL}(18: 2 / 20: 4 / 18: 2 / 16: 1)\end{array}$} & \multicolumn{3}{|c|}{ Control } & \multicolumn{3}{|c|}{ NAO+Light $0.5 \mathrm{~h}$} & \multicolumn{3}{|c|}{ NAO+Light $6 \mathrm{~h}$} & \multicolumn{3}{|c|}{ NAO+Light $48 \mathrm{~h}$} & \multicolumn{3}{|c|}{$\mathrm{NAOO}+$ Light+FCCP $0.5 \mathrm{~h}$} & \multicolumn{3}{|c|}{$\mathrm{NAO}+$ Light+FCCP 48h } \\
\hline & 1.1E-01 & \pm & $1.0 \mathrm{E}-02$ & $1.2 \mathrm{E}-01$ & \pm & $6.6 \mathrm{E}-03$ & $1.5 \mathrm{E}-01$ & \pm & $6.0 \mathrm{E}-03$ & $1.2 \mathrm{E}-01$ & \pm & $8.2 \mathrm{E}-03$ & $1.2 \mathrm{E}-01$ & \pm & $5.7 \mathrm{E}-03$ & $1.4 \mathrm{E}-01$ & \pm & $9.6 \mathrm{E}-03$ \\
\hline $\mathrm{CL}(18: 1 / 20: 3 / 18: 1 / 20: 3)$ & $5.9 \mathrm{E}-02$ & \pm & $5.0 \mathrm{E}-03$ & $9.4 \mathrm{E}-02$ & \pm & $2.3 \mathrm{E}-02$ & $8.0 \mathrm{E}-02$ & \pm & $2.2 \mathrm{E}-02$ & $4.8 \mathrm{E}-02$ & \pm & $1.3 \mathrm{E}-02$ & $8.3 \mathrm{E}-02$ & \pm & $3.1 \mathrm{E}-02$ & $6.0 \mathrm{E}-02$ & \pm & $1.7 \mathrm{E}-02$ \\
\hline $\mathrm{CL}(18: 1 / 22: 5 / 18: 2 / 18: 2)$ & $3.1 \mathrm{E}-02$ & \pm & $3.9 \mathrm{E}-03$ & $3.4 \mathrm{E}-02$ & \pm & $1.6 \mathrm{E}-03$ & 3.7E-02 & \pm & 4.6E-03 & $3.3 \mathrm{E}-02$ & \pm & $2.2 \mathrm{E}-03$ & $3.0 \mathrm{E}-02$ & \pm & $1.0 \mathrm{E}-03$ & $3.6 \mathrm{E}-02$ & \pm & $1.9 \mathrm{E}-03$ \\
\hline $\mathrm{CL}(18: 1 / 22: 5 / 18: 2 / 18: 2)-\mathrm{OOH}$ & $1.4 \mathrm{E}-03$ & \pm & $8.4 \mathrm{E}-04$ & $9.5 \mathrm{E}-04$ & \pm & 7.3E-04 & $6.3 \mathrm{E}-04$ & \pm & $5.8 \mathrm{E}-04$ & $2.1 \mathrm{E}-04$ & \pm & $3.7 \mathrm{E}-04$ & $4.4 \mathrm{E}-04$ & \pm & $2.9 \mathrm{E}-04$ & $1.0 \mathrm{E}-03$ & \pm & $8.5 \mathrm{E}-04$ \\
\hline $\mathrm{PC}(16: 0 / 18: 2)$ & $3.0 \mathrm{E}+01$ & \pm & $1.7 \mathrm{E}+00$ & $3.2 \mathrm{E}+01$ & \pm & $2.2 \mathrm{E}+00$ & $3.2 E+01$ & \pm & $6.7 \mathrm{E}-01$ & $3.3 E+01$ & \pm & $2.8 \mathrm{E}+00$ & $2.9 \mathrm{E}+01$ & \pm & $9.3 \mathrm{E}-02$ & $2.7 \mathrm{E}+01$ & \pm & $2.5 E+00$ \\
\hline $\mathrm{PC}(16: 0 / 18: 2)-\mathrm{OH}$ & $9.2 \mathrm{E}-02$ & \pm & $1.0 \mathrm{E}-02$ & 4.1E-01 & \pm & 4.1E-02 & $1.4 \mathrm{E}-01$ & \pm & $6.8 \mathrm{E}-03$ & N.D. & & & $1.8 \mathrm{E}-02$ & \pm & $4.2 \mathrm{E}-03$ & 1.1E-01 & \pm & $6.9 \mathrm{E}-03$ \\
\hline $\mathrm{PC}(16: 0 / 18: 2)-\mathrm{OOH}$ & N.D. & & & N.D. & & & N.D. & & & N.D. & & & N.D. & & & $3.3 \mathrm{E}-03$ & \pm & $3.0 \mathrm{E}-03$ \\
\hline $\mathrm{PC}(16: 0 / 20: 4)$ & $5.2 \mathrm{E}+01$ & \pm & $5.2 \mathrm{E}+00$ & $5.4 \mathrm{E}+01$ & \pm & $1.4 \mathrm{E}+00$ & $6.5 \mathrm{E}+01$ & \pm & 7.4E-01 & $4.7 \mathrm{E}+01$ & \pm & $1.7 \mathrm{E}+00$ & $5.9 \mathrm{E}+01$ & \pm & $2.3 E+00$ & $2.5 E+01$ & \pm & $4.5 \mathrm{E}-01$ \\
\hline $\mathrm{PC}(16: 0 / 20: 4)-\mathrm{OH}$ & N.D. & & & $1.6 \mathrm{E}-01$ & \pm & $6.3 \mathrm{E}-03$ & $1.1 \mathrm{E}-01$ & \pm & $1.1 \mathrm{E}-02$ & N.D. & & & $3.5 \mathrm{E}-02$ & \pm & $1.6 \mathrm{E}-02$ & $9.9 \mathrm{E}-02$ & \pm & $1.2 \mathrm{E}-02$ \\
\hline $\mathrm{PC}(16: 0 / 20: 4)-\mathrm{OOH}$ & N.D. & & & $2.8 \mathrm{E}-03$ & \pm & $7.8 \mathrm{E}-04$ & $1.9 \mathrm{E}-02$ & \pm & $3.3 \mathrm{E}-03$ & N.D. & & & $1.9 \mathrm{E}-03$ & \pm & $1.7 \mathrm{E}-03$ & $4.0 \mathrm{E}-03$ & \pm & $2.1 \mathrm{E}-03$ \\
\hline $\mathrm{PC}(16: 0 / 20: 5)$ & $8.9 E+00$ & \pm & $8.5 \mathrm{E}-01$ & $9.2 \mathrm{E}+00$ & \pm & $9.0 \mathrm{E}-02$ & $8.3 E+00$ & \pm & $2.7 \mathrm{E}-01$ & $8.2 E+00$ & \pm & $1.3 \mathrm{E}+00$ & $8.4 \mathrm{E}+00$ & \pm & $5.4 \mathrm{E}-01$ & $6.3 E+00$ & \pm & $2.6 \mathrm{E}-01$ \\
\hline $\mathrm{PC}(16: 0 / 20: 5)-\mathrm{OH}$ & N.D. & & & $1.8 \mathrm{E}-02$ & \pm & 7.4E-03 & $5.3 \mathrm{E}-03$ & \pm & $3.9 \mathrm{E}-03$ & N.D. & & & $1.7 \mathrm{E}-03$ & \pm & $1.4 \mathrm{E}-03$ & $6.5 \mathrm{E}-03$ & \pm & $1.8 \mathrm{E}-03$ \\
\hline $\mathrm{PC}(16: 0 / 20: 5)-\mathrm{OOH}$ & N.D. & & & N.D. & & & N.D. & & & N.D. & & & N.D. & & & $6.0 \mathrm{E}-04$ & \pm & $5.7 \mathrm{E}-04$ \\
\hline $\mathrm{PC}(16: 0 / 22: 6)$ & $1.1 \mathrm{E}+01$ & \pm & $9.9 \mathrm{E}-01$ & $1.2 \mathrm{E}+01$ & \pm & 4.1E-01 & $9.1 E+00$ & \pm & 4.5E-01 & $8.3 E+00$ & \pm & $3.6 \mathrm{E}-01$ & $8.8 \mathrm{E}+00$ & \pm & $3.2 \mathrm{E}-01$ & $9.0 E+00$ & \pm & $8.9 \mathrm{E}-01$ \\
\hline $\mathrm{PC}(16: 0 / 22: 6)-\mathrm{OH}$ & N.D. & & & $2.4 \mathrm{E}-02$ & \pm & $2.7 \mathrm{E}-03$ & $7.6 \mathrm{E}-03$ & \pm & $2.6 \mathrm{E}-03$ & N.D. & & & $2.7 \mathrm{E}-03$ & \pm & $9.7 \mathrm{E}-04$ & $4.9 \mathrm{E}-03$ & \pm & $2.4 \mathrm{E}-03$ \\
\hline $\mathrm{PC}(16: 0 / 22: 6)-\mathrm{OOH}$ & N.D. & & & N.D. & & & $7.8 \mathrm{E}-04$ & \pm & $6.8 \mathrm{E}-04$ & N.D. & & & N.D. & & & $6.0 \mathrm{E}-04$ & \pm & $5.7 \mathrm{E}-04$ \\
\hline $\mathrm{PC}(16: 1 / 18: 2)$ & $2.6 \mathrm{E}+00$ & \pm & 4.8E-02 & $2.6 \mathrm{E}+00$ & \pm & $2.0 \mathrm{E}-01$ & $2.8 \mathrm{E}+00$ & \pm & $2.0 \mathrm{E}-01$ & $2.8 \mathrm{E}+00$ & \pm & $3.0 \mathrm{E}-01$ & $2.8 \mathrm{E}+00$ & \pm & $1.3 \mathrm{E}-01$ & $2.3 E+00$ & \pm & 1.7E-01 \\
\hline $\mathrm{PC}(16: 1 / 18: 2)-\mathrm{OH}$ & $2.3 \mathrm{E}-02$ & \pm & $1.1 \mathrm{E}-02$ & $3.3 \mathrm{E}-03$ & \pm & $2.2 \mathrm{E}-03$ & $1.4 \mathrm{E}-03$ & \pm & $4.0 \mathrm{E}-04$ & N.D. & & & $8.9 \mathrm{E}-04$ & \pm & $1.5 \mathrm{E}-03$ & $1.1 \mathrm{E}-02$ & \pm & $4.5 \mathrm{E}-03$ \\
\hline $\mathrm{PC}(16: 1 / 18: 2)-\mathrm{OOH}$ & N.D. & & & N.D. & & & N.D. & & & N.D. & & & N.D. & & & N.D. & & \\
\hline $\mathrm{PC}(18: 0 / 18: 2)$ & $3.9 \mathrm{E}+01$ & \pm & $1.2 \mathrm{E}+00$ & $4.3 \mathrm{E}+01$ & \pm & $2.0 \mathrm{E}+00$ & $4.0 \mathrm{E}+01$ & \pm & $2.1 \mathrm{E}+00$ & $3.4 \mathrm{E}+01$ & \pm & $1.8 \mathrm{E}+00$ & $3.6 \mathrm{E}+01$ & \pm & $1.9 \mathrm{E}+00$ & $5.5 \mathrm{E}+01$ & \pm & $7.1 \mathrm{E}+00$ \\
\hline $\mathrm{PC}(18: 0 / 18: 2)-\mathrm{OH}$ & $5.6 \mathrm{E}-03$ & \pm & $5.0 \mathrm{E}-03$ & $1.3 \mathrm{E}-01$ & \pm & $1.6 \mathrm{E}-02$ & $3.9 \mathrm{E}-02$ & \pm & $3.0 \mathrm{E}-03$ & N.D. & & & 2.7E-03 & \pm & $2.9 \mathrm{E}-03$ & 4.1E-02 & \pm & 3.6E-03 \\
\hline $\mathrm{PC}(18: 0 / 18: 2)-\mathrm{OOH}$ & N.D. & & & $6.7 \mathrm{E}-04$ & \pm & $6.0 \mathrm{E}-04$ & $3.2 \mathrm{E}-03$ & \pm & $1.6 \mathrm{E}-03$ & N.D. & & & N.D. & & & $2.3 \mathrm{E}-03$ & \pm & $1.5 \mathrm{E}-03$ \\
\hline $\mathrm{PC}(18: 0 / 20: 3)$ & $3.7 \mathrm{E}+00$ & \pm & $2.2 \mathrm{E}-01$ & $4.8 \mathrm{E}+00$ & \pm & 4.4E-01 & $4.2 E+00$ & \pm & $3.0 \mathrm{E}-01$ & $2.6 \mathrm{E}+00$ & \pm & $8.5 \mathrm{E}-02$ & $3.7 \mathrm{E}+00$ & \pm & $2.3 \mathrm{E}-01$ & $4.9 \mathrm{E}+00$ & \pm & $1.5 \mathrm{E}-01$ \\
\hline $\mathrm{PC}(18: 0 / 20: 3)-\mathrm{OH}$ & N.D. & & & $6.7 \mathrm{E}-04$ & \pm & $5.8 \mathrm{E}-04$ & $1.3 \mathrm{E}-03$ & \pm & $4.0 \mathrm{E}-04$ & N.D. & & & N.D. & & & $2.0 \mathrm{E}-03$ & \pm & $4.5 \mathrm{E}-04$ \\
\hline $\mathrm{PC}(18: 0 / 20: 3)-\mathrm{OOH}$ & N.D. & & & N.D. & & & $2.4 \mathrm{E}-04$ & \pm & 4.2E-04 & N.D. & & & N.D. & & & N.D. & & \\
\hline $\mathrm{PC}(18: 0 / 20: 4)$ & $3.3 \mathrm{E}+01$ & \pm & $2.1 \mathrm{E}+00$ & $3.7 \mathrm{E}+01$ & \pm & $1.3 \mathrm{E}+00$ & $3.8 \mathrm{E}+01$ & \pm & $2.0 \mathrm{E}+00$ & 3.2E+01 & \pm & $2.4 \mathrm{E}+00$ & $3.6 \mathrm{E}+01$ & \pm & $2.4 \mathrm{E}+00$ & $2.1 \mathrm{E}+01$ & \pm & $9.5 \mathrm{E}-01$ \\
\hline $\mathrm{PC}(18: 0 / 20: 4)-\mathrm{OH}$ & N.D. & & & $8.9 \mathrm{E}-02$ & \pm & $1.3 \mathrm{E}-02$ & $5.4 \mathrm{E}-02$ & \pm & $3.2 \mathrm{E}-03$ & N.D. & & & $4.9 \mathrm{E}-03$ & \pm & $3.4 \mathrm{E}-03$ & 7.3E-02 & \pm & $5.7 \mathrm{E}-03$ \\
\hline $\mathrm{PC}(18: 0 / 20: 4)-\mathrm{OOH}$ & N.D. & & & $1.7 \mathrm{E}-03$ & \pm & $6.7 \mathrm{E}-04$ & $1.3 \mathrm{E}-02$ & \pm & $1.4 \mathrm{E}-03$ & N.D. & & & $5.6 \mathrm{E}-04$ & \pm & $9.8 \mathrm{E}-04$ & 4.4E-03 & \pm & $2.5 \mathrm{E}-03$ \\
\hline $\mathrm{PC}(18: 0 / 22: 4)$ & $1.9 \mathrm{E}+00$ & \pm & $1.7 \mathrm{E}-01$ & $2.3 \mathrm{E}+00$ & \pm & $7.8 \mathrm{E}-02$ & $2.3 \mathrm{E}+00$ & \pm & $5.9 \mathrm{E}-02$ & $2.3 E+00$ & \pm & $5.8 \mathrm{E}-01$ & $2.4 \mathrm{E}+00$ & \pm & $1.3 \mathrm{E}-01$ & $2.5 \mathrm{E}+00$ & \pm & 1.3E-01 \\
\hline $\mathrm{PC}(18: 0 / 22: 4)-\mathrm{OOH}$ & N.D. & & & N.D. & & & N.D. & & & N.D. & & & N.D. & & & N.D. & & \\
\hline $\mathrm{PC}(18: 0 / 22: 6)$ & $7.0 \mathrm{E}+00$ & \pm & $6.7 \mathrm{E}-01$ & $7.1 \mathrm{E}+00$ & \pm & $2.8 \mathrm{E}-01$ & $6.3 E+00$ & \pm & 4.6E-01 & $5.8 \mathrm{E}+00$ & \pm & $2.2 \mathrm{E}-01$ & $5.9 \mathrm{E}+00$ & \pm & $2.8 \mathrm{E}-01$ & $6.3 E+00$ & \pm & $1.9 \mathrm{E}-01$ \\
\hline $\mathrm{PC}(18: 0 / 22: 6)-\mathrm{OH}$ & N.D. & & & $5.1 \mathrm{E}-03$ & \pm & $5.3 \mathrm{E}-03$ & $2.2 \mathrm{E}-03$ & \pm & $1.6 \mathrm{E}-03$ & N.D. & & & N.D. & & & $1.6 \mathrm{E}-03$ & \pm & $1.5 \mathrm{E}-03$ \\
\hline $\mathrm{PC}(18: 0 / 22: 6)-\mathrm{OOH}$ & N.D. & & & N.D. & & & N.D. & & & N.D. & & & N.D. & & & $2.3 \mathrm{E}-04$ & \pm & $4.0 \mathrm{E}-04$ \\
\hline $\mathrm{PC}(18: 1 / 18: 2)$ & $1.7 \mathrm{E}+01$ & \pm & $3.8 \mathrm{E}-01$ & $1.9 \mathrm{E}+01$ & \pm & $9.8 \mathrm{E}-01$ & $1.9 \mathrm{E}+01$ & \pm & $1.5 \mathrm{E}-01$ & $1.5 \mathrm{E}+01$ & \pm & $1.8 \mathrm{E}+00$ & $1.7 \mathrm{E}+01$ & \pm & $8.4 \mathrm{E}-01$ & $1.4 \mathrm{E}+01$ & \pm & $1.2 \mathrm{E}+00$ \\
\hline $\mathrm{PC}(18: 1 / 18: 2)-\mathrm{OH}$ & N.D. & & & $4.4 \mathrm{E}-02$ & \pm & $9.8 \mathrm{E}-03$ & $2.3 \mathrm{E}-02$ & \pm & $5.9 \mathrm{E}-03$ & N.D. & & & $3.9 \mathrm{E}-03$ & \pm & 1.7E-03 & $3.8 \mathrm{E}-02$ & \pm & $5.8 \mathrm{E}-03$ \\
\hline $\mathrm{PC}(18: 1 / 18: 2)-\mathrm{OOH}$ & N.D. & & & $8.2 \mathrm{E}-04$ & \pm & $7.7 \mathrm{E}-04$ & $1.9 \mathrm{E}-03$ & \pm & $1.6 \mathrm{E}-03$ & N.D. & & & $1.1 \mathrm{E}-03$ & \pm & $1.9 \mathrm{E}-03$ & $3.8 \mathrm{E}-04$ & \pm & $3.4 \mathrm{E}-04$ \\
\hline $\mathrm{PC}(18: 1 / 20: 4)$ & $3.4 \mathrm{E}+01$ & \pm & $2.1 \mathrm{E}+00$ & $3.6 \mathrm{E}+01$ & \pm & $9.4 \mathrm{E}-01$ & $4.0 \mathrm{E}+01$ & \pm & $2.1 \mathrm{E}+00$ & $2.6 \mathrm{E}+01$ & \pm & $1.4 \mathrm{E}+00$ & $3.5 \mathrm{E}+01$ & \pm & $2.3 E+00$ & $2.1 \mathrm{E}+01$ & \pm & 7.1E-01 \\
\hline
\end{tabular}




\begin{tabular}{|c|c|c|c|c|c|c|c|c|c|c|c|c|c|c|c|c|c|c|}
\hline \multirow{2}{*}{$\begin{array}{l}\text { Lipids } \\
\mathrm{PC}(18: 1 / 20: 4)-\mathrm{OH}\end{array}$} & \multicolumn{3}{|c|}{ Control } & \multicolumn{3}{|c|}{ NAO+Light $0.5 \mathrm{~h}$} & \multicolumn{3}{|c|}{ NAO+Light $6 \mathrm{~h}$} & \multicolumn{3}{|c|}{$\mathrm{NAO}+$ Light $48 \mathrm{~h}$} & \multicolumn{3}{|c|}{$\mathrm{NAO}+$ Light+FCCP $0.5 \mathrm{~h}$} & \multicolumn{3}{|c|}{$\mathrm{NAO+Light+FCCP} 48 \mathrm{~h}$} \\
\hline & $3.1 \mathrm{E}-03$ & \pm & $5.4 \mathrm{E}-03$ & $1.1 \mathrm{E}-01$ & \pm & $3.6 \mathrm{E}-03$ & $5.8 \mathrm{E}-02$ & \pm & $6.4 \mathrm{E}-03$ & N.D. & & & $1.5 \mathrm{E}-02$ & \pm & $6.7 \mathrm{E}-03$ & $5.7 \mathrm{E}-02$ & \pm & $1.1 \mathrm{E}-02$ \\
\hline $\mathrm{PC}(18: 1 / 20: 4)-\mathrm{OOH}$ & N.D. & & & $1.1 \mathrm{E}-03$ & \pm & $1.1 \mathrm{E}-03$ & $9.8 \mathrm{E}-03$ & \pm & $1.8 \mathrm{E}-03$ & N.D. & & & N.D. & & & $1.9 \mathrm{E}-03$ & \pm & $1.7 \mathrm{E}-03$ \\
\hline $\mathrm{PC}(18: 1 / 22: 6)$ & $4.5 \mathrm{E}+00$ & \pm & $4.0 \mathrm{E}-01$ & $4.7 \mathrm{E}+00$ & \pm & $1.9 \mathrm{E}-01$ & $4.2 E+00$ & \pm & $1.6 \mathrm{E}-01$ & $2.6 \mathrm{E}+00$ & \pm & $1.5 \mathrm{E}-01$ & $4.5 \mathrm{E}+00$ & \pm & $1.2 \mathrm{E}-01$ & $3.9 \mathrm{E}+00$ & \pm & $2.6 \mathrm{E}-01$ \\
\hline $\mathrm{PC}(18: 1 / 22: 6)-\mathrm{OH}$ & N.D. & & & $1.5 \mathrm{E}-03$ & \pm & $1.4 \mathrm{E}-03$ & N.D. & & & N.D. & & & N.D. & & & $3.9 \mathrm{E}-04$ & \pm & $6.7 \mathrm{E}-04$ \\
\hline $\mathrm{PC}(18: 1 / 22: 6)-\mathrm{OOH}$ & N.D. & & & $2.2 \mathrm{E}-04$ & \pm & $3.9 \mathrm{E}-04$ & N.D. & & & N.D. & & & N.D. & & & $3.8 \mathrm{E}-04$ & \pm & $6.5 \mathrm{E}-04$ \\
\hline $\mathrm{PC}(18: 2 / 20: 5)$ & $5.1 \mathrm{E}-01$ & \pm & $1.4 \mathrm{E}-02$ & $6.2 \mathrm{E}-01$ & \pm & $1.8 \mathrm{E}-02$ & $5.7 \mathrm{E}-01$ & \pm & $3.1 \mathrm{E}-02$ & N.D. & & & $6.2 \mathrm{E}-01$ & \pm & $2.4 \mathrm{E}-02$ & 4.7E-01 & \pm & $4.5 \mathrm{E}-02$ \\
\hline $\mathrm{PC}(20: 0 / 20: 5)$ & $6.0 \mathrm{E}+00$ & \pm & $3.6 \mathrm{E}-01$ & $7.5 \mathrm{E}+00$ & \pm & $1.5 \mathrm{E}-01$ & $7.5 \mathrm{E}+00$ & \pm & $1.7 \mathrm{E}-01$ & $5.1 \mathrm{E}+00$ & \pm & $6.3 \mathrm{E}-01$ & $6.2 E+00$ & \pm & $5.8 \mathrm{E}-01$ & $5.6 \mathrm{E}+00$ & \pm & $5.6 \mathrm{E}-01$ \\
\hline $\mathrm{PC}(20: 0 / 20: 5)-\mathrm{OH}$ & N.D. & & & $1.3 \mathrm{E}-03$ & \pm & $1.3 \mathrm{E}-03$ & $2.3 \mathrm{E}-03$ & \pm & $6.8 \mathrm{E}-04$ & N.D. & & & $1.2 \mathrm{E}-03$ & \pm & $2.0 \mathrm{E}-03$ & $1.3 \mathrm{E}-03$ & \pm & $1.2 \mathrm{E}-03$ \\
\hline $\mathrm{PC}(20: 0 / 20: 5)-\mathrm{OOH}$ & N.D. & & & N.D. & & & N.D. & & & N.D. & & & N.D. & & & $2.7 \mathrm{E}-04$ & \pm & $4.7 \mathrm{E}-04$ \\
\hline $\mathrm{PC}(20: 3 / 22: 6)$ & $1.4 \mathrm{E}+00$ & \pm & $4.3 \mathrm{E}-02$ & $1.9 \mathrm{E}+00$ & \pm & $1.5 \mathrm{E}-01$ & $2.8 \mathrm{E}+00$ & \pm & $1.3 \mathrm{E}-01$ & $1.2 \mathrm{E}-01$ & \pm & $8.0 \mathrm{E}-02$ & $2.7 E+00$ & \pm & $2.4 \mathrm{E}-02$ & $3.6 \mathrm{E}-01$ & \pm & $9.1 \mathrm{E}-03$ \\
\hline $\mathrm{PC}(20: 4 / 20: 4)$ & $8.3 \mathrm{E}-01$ & \pm & $6.6 \mathrm{E}-02$ & $1.6 \mathrm{E}+00$ & \pm & $1.2 \mathrm{E}-01$ & $2.1 \mathrm{E}+00$ & \pm & $6.5 \mathrm{E}-02$ & $1.4 \mathrm{E}-01$ & \pm & $5.6 \mathrm{E}-02$ & $2.5 \mathrm{E}+00$ & \pm & $2.6 \mathrm{E}-01$ & 4.1E-01 & \pm & $2.6 \mathrm{E}-02$ \\
\hline $\mathrm{PC}(20: 4 / 22: 4)$ & $9.3 \mathrm{E}-01$ & \pm & $1.9 \mathrm{E}-01$ & $1.3 \mathrm{E}+00$ & \pm & $4.3 \mathrm{E}-02$ & $1.9 \mathrm{E}+00$ & \pm & $5.2 \mathrm{E}-02$ & 7.7E-02 & \pm & $6.4 \mathrm{E}-02$ & $1.9 \mathrm{E}+00$ & \pm & $3.1 \mathrm{E}-02$ & $2.7 \mathrm{E}-01$ & \pm & $2.4 \mathrm{E}-02$ \\
\hline $\mathrm{PC}(20: 4 / 22: 4)-\mathrm{OH}$ & $3.2 \mathrm{E}-02$ & \pm & $2.9 \mathrm{E}-02$ & $8.0 \mathrm{E}-04$ & \pm & $1.4 \mathrm{E}-03$ & $1.2 \mathrm{E}-03$ & \pm & $9.0 \mathrm{E}-04$ & $1.8 \mathrm{E}-01$ & \pm & $5.2 \mathrm{E}-02$ & $2.2 \mathrm{E}-03$ & \pm & $2.3 \mathrm{E}-03$ & $2.3 \mathrm{E}-03$ & \pm & $1.3 \mathrm{E}-03$ \\
\hline $\mathrm{PC}(20: 5 / 22: 5)$ & $5.2 \mathrm{E}-01$ & \pm & $8.6 \mathrm{E}-02$ & $1.1 \mathrm{E}+00$ & \pm & $1.3 \mathrm{E}-01$ & $1.2 E+00$ & \pm & $1.0 \mathrm{E}-01$ & $1.5 \mathrm{E}-02$ & \pm & $2.6 \mathrm{E}-02$ & $1.6 \mathrm{E}+00$ & \pm & $1.2 \mathrm{E}-01$ & $3.6 \mathrm{E}-01$ & \pm & 1.1E-02 \\
\hline $\mathrm{PC}(\mathrm{O}-16: 0 / 18: 2)$ & $3.9 E+00$ & \pm & $2.1 \mathrm{E}-01$ & $4.1 \mathrm{E}+00$ & \pm & $3.7 \mathrm{E}-01$ & $4.2 E+00$ & \pm & $1.9 \mathrm{E}-01$ & $1.8 \mathrm{E}+00$ & \pm & $1.2 \mathrm{E}-02$ & $3.6 \mathrm{E}+00$ & \pm & $1.2 \mathrm{E}-01$ & $5.7 \mathrm{E}+00$ & \pm & $3.0 \mathrm{E}-01$ \\
\hline $\mathrm{PC}(\mathrm{O}-16: 0 / 18: 2)-\mathrm{OOH}$ & $7.2 \mathrm{E}-02$ & \pm & $2.5 \mathrm{E}-02$ & $1.2 \mathrm{E}-01$ & \pm & $2.2 \mathrm{E}-03$ & $1.4 \mathrm{E}-01$ & \pm & $2.3 \mathrm{E}-02$ & $3.2 \mathrm{E}-02$ & \pm & $2.8 \mathrm{E}-02$ & $1.9 \mathrm{E}-01$ & \pm & $4.2 \mathrm{E}-02$ & $3.9 \mathrm{E}-01$ & \pm & $2.2 \mathrm{E}-02$ \\
\hline $\mathrm{PC}(\mathrm{O}-16: 0 / 20: 3)$ & $1.6 \mathrm{E}+00$ & \pm & $1.1 \mathrm{E}-01$ & $1.9 \mathrm{E}+00$ & \pm & $8.1 \mathrm{E}-02$ & $1.8 \mathrm{E}+00$ & \pm & $8.2 \mathrm{E}-02$ & $1.9 \mathrm{E}-01$ & \pm & $5.6 \mathrm{E}-02$ & $1.6 \mathrm{E}+00$ & \pm & $9.0 \mathrm{E}-02$ & $3.3 \mathrm{E}+00$ & \pm & $6.9 \mathrm{E}-02$ \\
\hline $\mathrm{PC}(\mathrm{O}-16: 0 / 20: 3)-\mathrm{OOH}$ & $5.7 \mathrm{E}-03$ & \pm & $5.1 \mathrm{E}-03$ & $1.4 \mathrm{E}-01$ & \pm & 1.7E-02 & $3.9 \mathrm{E}-02$ & \pm & 3. $3 \mathrm{E}-03$ & N.D. & & & $2.6 \mathrm{E}-03$ & \pm & $2.8 \mathrm{E}-03$ & 4.1E-02 & \pm & $2.7 \mathrm{E}-03$ \\
\hline $\mathrm{PC}(\mathrm{O}-16: 0 / 20: 4)$ & $3.5 \mathrm{E}+00$ & \pm & $2.8 \mathrm{E}-01$ & $4.6 \mathrm{E}+00$ & \pm & 2.4E-01 & $5.5 \mathrm{E}+00$ & \pm & $4.2 \mathrm{E}-01$ & $3.8 \mathrm{E}+00$ & \pm & $6.9 \mathrm{E}-01$ & $4.7 \mathrm{E}+00$ & \pm & $2.9 \mathrm{E}-01$ & $3.6 \mathrm{E}+00$ & \pm & $3.1 \mathrm{E}-01$ \\
\hline $\mathrm{PC}(\mathrm{O}-16: 0 / 20: 4)-\mathrm{OOH}$ & N.D. & & & $4.4 \mathrm{E}-02$ & \pm & $8.8 \mathrm{E}-03$ & $2.2 \mathrm{E}-02$ & \pm & $4.1 \mathrm{E}-03$ & N.D. & & & $3.5 \mathrm{E}-03$ & \pm & $1.5 \mathrm{E}-03$ & $3.8 \mathrm{E}-02$ & \pm & $6.0 \mathrm{E}-03$ \\
\hline $\mathrm{PC}(\mathrm{O}-18: 0 / 20: 4)$ & $2.7 \mathrm{E}+00$ & \pm & $3.7 \mathrm{E}-01$ & $4.1 \mathrm{E}+00$ & \pm & $1.6 \mathrm{E}-01$ & $5.0 \mathrm{E}+00$ & \pm & $5.0 \mathrm{E}-01$ & $2.5 \mathrm{E}+00$ & \pm & 2.7E-01 & $3.7 \mathrm{E}+00$ & \pm & $2.2 \mathrm{E}-01$ & $3.5 \mathrm{E}+00$ & \pm & $3.0 \mathrm{E}-01$ \\
\hline $\mathrm{PC}(\mathrm{O}-18: 0 / 20: 4)-\mathrm{OOH}$ & N.D. & & & $6.3 \mathrm{E}-04$ & \pm & $5.5 \mathrm{E}-04$ & $1.4 \mathrm{E}-03$ & \pm & $4.6 \mathrm{E}-04$ & N.D. & & & N.D. & & & $2.0 \mathrm{E}-03$ & \pm & $5.2 \mathrm{E}-04$ \\
\hline $\mathrm{PC}(\mathrm{O}-18: 1 / 20: 4)$ & $6.4 \mathrm{E}+00$ & \pm & 4.1E-01 & $5.8 \mathrm{E}+00$ & \pm & $1.1 \mathrm{E}-01$ & $6.2 E+00$ & \pm & $3.2 \mathrm{E}-01$ & $7.3 \mathrm{E}+00$ & \pm & $5.9 \mathrm{E}-01$ & $5.6 \mathrm{E}+00$ & \pm & $4.8 \mathrm{E}-01$ & $6.9 \mathrm{E}+00$ & \pm & $7.5 \mathrm{E}-01$ \\
\hline $\mathrm{PC}(\mathrm{O}-18: 1 / 20: 4)-\mathrm{OOH}$ & N.D. & & & $8.4 \mathrm{E}-02$ & \pm & $9.3 \mathrm{E}-03$ & $5.5 \mathrm{E}-02$ & \pm & $4.3 \mathrm{E}-03$ & N.D. & & & $3.6 \mathrm{E}-03$ & \pm & $9.4 \mathrm{E}-04$ & 7.6E-02 & \pm & $5.2 \mathrm{E}-03$ \\
\hline $\mathrm{PC}(\mathrm{P}-16: 0 / 20: 4)$ & $3.6 \mathrm{E}+00$ & \pm & $6.1 \mathrm{E}-01$ & $3.9 \mathrm{E}+00$ & \pm & $2.4 \mathrm{E}-01$ & $4.1 \mathrm{E}+00$ & \pm & $9.8 \mathrm{E}-02$ & $4.3 \mathrm{E}+00$ & \pm & $5.0 \mathrm{E}-01$ & $3.9 \mathrm{E}+00$ & \pm & $1.6 \mathrm{E}-01$ & $3.8 \mathrm{E}+00$ & \pm & $1.5 \mathrm{E}-01$ \\
\hline $\mathrm{PC}(\mathrm{P}-18: 0 / 20: 5)$ & $4.0 E+00$ & \pm & $3.0 \mathrm{E}-01$ & $4.0 \mathrm{E}+00$ & \pm & $1.2 \mathrm{E}-01$ & $3.8 \mathrm{E}+00$ & \pm & $4.1 \mathrm{E}-01$ & $3.7 \mathrm{E}+00$ & \pm & $1.9 \mathrm{E}-01$ & $3.5 \mathrm{E}+00$ & \pm & $6.5 \mathrm{E}-02$ & $4.7 \mathrm{E}+00$ & \pm & $4.0 \mathrm{E}-01$ \\
\hline $\mathrm{PC}(\mathrm{P}-18: 0 / 20: 5)-\mathrm{OOH}$ & $2.7 \mathrm{E}-03$ & \pm & $4.6 \mathrm{E}-03$ & $1.2 \mathrm{E}-01$ & \pm & $4.0 \mathrm{E}-03$ & $5.9 \mathrm{E}-02$ & \pm & $6.7 \mathrm{E}-03$ & N.D. & & & $1.5 \mathrm{E}-02$ & \pm & $7.1 \mathrm{E}-03$ & $5.7 \mathrm{E}-02$ & \pm & $5.0 \mathrm{E}-03$ \\
\hline $\mathrm{PC}(\mathrm{P}-18: 0 / 22: 4)$ & $1.5 \mathrm{E}+00$ & \pm & $7.2 \mathrm{E}-02$ & $2.0 \mathrm{E}+00$ & \pm & $9.0 \mathrm{E}-03$ & $1.7 \mathrm{E}+00$ & \pm & $1.4 \mathrm{E}-01$ & $1.3 \mathrm{E}-01$ & \pm & $1.3 \mathrm{E}-01$ & $1.5 \mathrm{E}+00$ & \pm & $1.1 \mathrm{E}-01$ & $2.1 \mathrm{E}+00$ & \pm & $1.4 \mathrm{E}-01$ \\
\hline $\mathrm{PC}(\mathrm{P}-18: 0 / 22: 4)-\mathrm{OH}$ & N.D. & & & N.D. & & & N.D. & & & N.D. & & & N.D. & & & $7.0 \mathrm{E}-03$ & \pm & $5.0 \mathrm{E}-03$ \\
\hline $\operatorname{PE}(16: 0 / 22: 6)$ & $3.1 E+00$ & \pm & $2.0 \mathrm{E}-01$ & $3.0 \mathrm{E}+00$ & \pm & $3.3 \mathrm{E}-01$ & $2.5 \mathrm{E}+00$ & \pm & $1.3 \mathrm{E}-01$ & $2.7 \mathrm{E}+00$ & \pm & $4.8 \mathrm{E}-01$ & $3.1 \mathrm{E}+00$ & \pm & $2.5 \mathrm{E}-01$ & $3.1 \mathrm{E}+00$ & \pm & $1.5 \mathrm{E}-01$ \\
\hline $\mathrm{PE}(16: 0 / 22: 6)-\mathrm{OH}$ & $9.3 \mathrm{E}-03$ & \pm & $1.3 \mathrm{E}-03$ & $5.3 \mathrm{E}-02$ & \pm & $1.5 \mathrm{E}-03$ & $6.7 \mathrm{E}-02$ & \pm & $9.7 \mathrm{E}-03$ & N.D. & & & $3.3 \mathrm{E}-02$ & \pm & $5.0 \mathrm{E}-03$ & $2.8 \mathrm{E}-02$ & \pm & $5.4 \mathrm{E}-03$ \\
\hline $\mathrm{PE}(16: 0 / 22: 6)-\mathrm{OOH}$ & $1.2 \mathrm{E}-03$ & \pm & $2.1 \mathrm{E}-03$ & $7.4 \mathrm{E}-04$ & \pm & $6.6 \mathrm{E}-04$ & $1.1 \mathrm{E}-03$ & \pm & 1.1E-03 & N.D. & & & N.D. & & & $5.7 \mathrm{E}-04$ & \pm & 7.1E-04 \\
\hline $\mathrm{PE}(18: 0 / 18: 1)$ & $9.2 \mathrm{E}-03$ & \pm & $1.1 \mathrm{E}-03$ & $5.0 \mathrm{E}-02$ & \pm & $4.0 \mathrm{E}-03$ & $6.9 \mathrm{E}-02$ & \pm & $3.1 \mathrm{E}-03$ & N.D. & & & 3.3E-02 & \pm & $6.6 \mathrm{E}-03$ & 2.7E-02 & \pm & $6.7 \mathrm{E}-03$ \\
\hline $\mathrm{PE}(18: 0 / 18: 2)-\mathrm{OH}$ & $2.8 \mathrm{E}-02$ & \pm & $1.1 \mathrm{E}-02$ & $3.5 \mathrm{E}-02$ & \pm & $1.2 \mathrm{E}-02$ & $5.3 \mathrm{E}-02$ & \pm & $5.6 \mathrm{E}-03$ & $9.5 \mathrm{E}-03$ & \pm & $1.6 \mathrm{E}-02$ & $2.0 \mathrm{E}-02$ & \pm & $6.7 \mathrm{E}-03$ & $2.6 \mathrm{E}-02$ & \pm & $7.4 \mathrm{E}-03$ \\
\hline $\operatorname{PE}(18: 0 / 20: 4)$ & $7.3 E+01$ & \pm & $2.0 E+00$ & $6.9 \mathrm{E}+01$ & \pm & $4.3 E+00$ & $7.0 \mathrm{E}+01$ & \pm & $1.1 \mathrm{E}+00$ & $7.5 \mathrm{E}+01$ & \pm & $3.4 \mathrm{E}+00$ & $6.1 \mathrm{E}+01$ & \pm & $4.5 \mathrm{E}+00$ & $6.5 \mathrm{E}+01$ & \pm & $2.3 E+00$ \\
\hline $\mathrm{PE}(18: 0 / 20: 4)-\mathrm{OH}$ & 1.3E-01 & \pm & $2.4 \mathrm{E}-02$ & $2.0 \mathrm{E}-01$ & \pm & $1.0 \mathrm{E}-02$ & 2.2E-01 & \pm & $7.7 \mathrm{E}-03$ & $5.2 \mathrm{E}-02$ & \pm & $2.8 \mathrm{E}-02$ & 4.0E-02 & \pm & $2.1 \mathrm{E}-02$ & 7.5E-02 & \pm & $7.1 \mathrm{E}-03$ \\
\hline $\mathrm{PE}(18: 0 / 20: 4)-\mathrm{OOH}$ & N.D. & & & $1.5 \mathrm{E}-03$ & \pm & 7.6E-04 & $6.2 \mathrm{E}-03$ & \pm & $3.7 \mathrm{E}-03$ & N.D. & & & N.D. & & & $4.6 \mathrm{E}-03$ & \pm & $1.6 \mathrm{E}-03$ \\
\hline
\end{tabular}




\begin{tabular}{|c|c|c|c|c|c|c|c|c|c|c|c|c|c|c|c|c|c|c|}
\hline \multirow{2}{*}{$\begin{array}{l}\text { Lipids } \\
P E(18: 0 / 22: 2)\end{array}$} & \multicolumn{3}{|c|}{ Control } & \multicolumn{3}{|c|}{$\mathrm{NAO+}+$ Light $0.5 \mathrm{~h}$} & \multicolumn{3}{|c|}{ NAO+Light $6 \mathrm{~h}$} & \multicolumn{3}{|c|}{ NAO+Light 48h } & \multicolumn{3}{|c|}{ NAO+Light+FCCP 0.5h } & \multicolumn{3}{|c|}{ NAO+Light+FCCP 48h } \\
\hline & $2.5 \mathrm{E}-01$ & \pm & $9.1 \mathrm{E}-02$ & $2.2 \mathrm{E}-01$ & \pm & $5.1 \mathrm{E}-02$ & $2.8 \mathrm{E}-01$ & \pm & $3.9 \mathrm{E}-02$ & $7.6 \mathrm{E}-03$ & \pm & $1.3 \mathrm{E}-02$ & $1.9 \mathrm{E}-01$ & \pm & $7.2 \mathrm{E}-02$ & $3.0 \mathrm{E}-01$ & \pm & $5.8 \mathrm{E}-02$ \\
\hline $\mathrm{PE}(18: 0 / 22: 2)-\mathrm{OH}$ & N.D. & & & N.D. & & & $8.0 \mathrm{E}-04$ & \pm & $1.0 \mathrm{E}-04$ & N.D. & & & N.D. & & & N.D. & & \\
\hline $\mathrm{PE}(18: 0 / 22: 6)$ & $5.0 \mathrm{E}+00$ & \pm & $3.9 \mathrm{E}-01$ & $4.8 \mathrm{E}+00$ & \pm & $1.4 \mathrm{E}-01$ & $4.8 \mathrm{E}+00$ & \pm & $2.0 \mathrm{E}-01$ & $6.0 E+00$ & \pm & $3.6 \mathrm{E}-01$ & $5.2 E+00$ & \pm & $1.3 \mathrm{E}-01$ & $4.7 \mathrm{E}+00$ & \pm & $1.8 \mathrm{E}-01$ \\
\hline $\mathrm{PE}(18: 0 / 22: 6)-\mathrm{OOH}$ & $2.3 \mathrm{E}-02$ & \pm & $1.0 \mathrm{E}-02$ & $4.2 \mathrm{E}-03$ & \pm & $1.0 \mathrm{E}-03$ & $8.7 \mathrm{E}-03$ & \pm & $3.8 \mathrm{E}-03$ & N.D. & & & $5.2 \mathrm{E}-03$ & \pm & $2.6 \mathrm{E}-03$ & 4.6E-03 & \pm & $1.1 \mathrm{E}-03$ \\
\hline $\mathrm{PE}(18: 1 / 18: 2)$ & $1.5 E+00$ & \pm & $1.3 \mathrm{E}-01$ & $2.3 E+00$ & \pm & $1.0 \mathrm{E}-01$ & $3.2 E+00$ & \pm & $1.5 \mathrm{E}-01$ & $2.4 \mathrm{E}+00$ & \pm & $7.8 \mathrm{E}-01$ & $2.5 \mathrm{E}+00$ & \pm & $2.9 \mathrm{E}-01$ & $3.1 \mathrm{E}+00$ & \pm & 1.4E-01 \\
\hline $\mathrm{PE}(18: 1 / 18: 2)-\mathrm{OH}$ & $1.5 \mathrm{E}-02$ & \pm & $1.0 \mathrm{E}-02$ & $1.5 \mathrm{E}-02$ & \pm & $2.6 \mathrm{E}-03$ & $2.9 \mathrm{E}-02$ & \pm & $2.4 \mathrm{E}-03$ & N.D. & & & $1.4 \mathrm{E}-02$ & \pm & $1.4 \mathrm{E}-03$ & $1.6 \mathrm{E}-02$ & \pm & $2.1 \mathrm{E}-03$ \\
\hline$P E(18: 2 / 18: 2)$ & $7.4 \mathrm{E}+00$ & \pm & $2.6 \mathrm{E}-01$ & $7.4 \mathrm{E}+00$ & \pm & $1.7 \mathrm{E}-01$ & $7.7 \mathrm{E}+00$ & \pm & $8.1 \mathrm{E}-01$ & $8.6 \mathrm{E}+00$ & \pm & 7.3E-01 & $7.6 \mathrm{E}+00$ & \pm & $2.3 \mathrm{E}-01$ & $6.4 \mathrm{E}+00$ & \pm & $3.1 \mathrm{E}-01$ \\
\hline $\mathrm{PE}(18: 2 / 18: 2)-\mathrm{OH}$ & $1.8 \mathrm{E}-03$ & \pm & $3.2 \mathrm{E}-03$ & $1.2 \mathrm{E}-02$ & \pm & $2.9 \mathrm{E}-03$ & $1.3 \mathrm{E}-02$ & \pm & $3.8 \mathrm{E}-03$ & N.D. & & & $1.4 \mathrm{E}-03$ & \pm & $2.4 \mathrm{E}-03$ & $8.6 \mathrm{E}-03$ & \pm & $1.4 \mathrm{E}-03$ \\
\hline $\mathrm{PE}(18: 2 / 18: 2)-\mathrm{OOH}$ & N.D. & & & N.D. & & & $3.3 \mathrm{E}-04$ & \pm & $5.8 \mathrm{E}-04$ & N.D. & & & N.D. & & & $2.3 \mathrm{E}-04$ & \pm & $4.0 \mathrm{E}-04$ \\
\hline $\operatorname{PE}(20: 1 / 20: 4)$ & $5.3 \mathrm{E}+00$ & \pm & $6.6 \mathrm{E}-02$ & $5.1 \mathrm{E}+00$ & \pm & $2.3 \mathrm{E}-01$ & $6.0 \mathrm{E}+00$ & \pm & $2.3 \mathrm{E}-01$ & $7.5 \mathrm{E}+00$ & \pm & $6.5 \mathrm{E}-01$ & $6.0 \mathrm{E}+00$ & \pm & $3.4 \mathrm{E}-01$ & $4.3 E+00$ & \pm & $1.9 \mathrm{E}-01$ \\
\hline $\mathrm{PE}(20: 1 / 20: 4)-\mathrm{OH}$ & $5.9 \mathrm{E}-01$ & \pm & $3.8 \mathrm{E}-02$ & $2.6 \mathrm{E}-01$ & \pm & $8.9 \mathrm{E}-03$ & $1.8 \mathrm{E}-01$ & \pm & $6.7 \mathrm{E}-03$ & $9.1 \mathrm{E}-02$ & \pm & $1.7 \mathrm{E}-02$ & $1.0 \mathrm{E}-01$ & \pm & $1.8 \mathrm{E}-02$ & $8.9 \mathrm{E}-02$ & \pm & $1.9 \mathrm{E}-03$ \\
\hline $\mathrm{PE}(20: 1 / 20: 4)-\mathrm{OOH}$ & $3.8 \mathrm{E}-03$ & \pm & $6.6 \mathrm{E}-04$ & $6.4 \mathrm{E}-04$ & \pm & $5.6 \mathrm{E}-04$ & $6.9 \mathrm{E}-03$ & \pm & $4.8 \mathrm{E}-03$ & N.D. & & & $6.7 \mathrm{E}-03$ & \pm & $5.0 \mathrm{E}-03$ & $6.2 \mathrm{E}-03$ & \pm & $3.7 \mathrm{E}-03$ \\
\hline $\mathrm{PE}(16: 1 / 20: 4)$ & $1.0 E+00$ & \pm & $6.0 \mathrm{E}-02$ & $1.3 E+00$ & \pm & $7.3 \mathrm{E}-02$ & $1.0 \mathrm{E}+00$ & \pm & 7.1E-02 & $6.6 \mathrm{E}-01$ & \pm & $1.6 \mathrm{E}-01$ & $1.1 \mathrm{E}+00$ & \pm & $4.0 \mathrm{E}-02$ & $1.2 \mathrm{E}+00$ & \pm & $5.8 \mathrm{E}-02$ \\
\hline $\mathrm{PE}(16: 1 / 20: 4)-\mathrm{OH}$ & N.D. & & & $1.8 \mathrm{E}-03$ & \pm & $2.7 \mathrm{E}-04$ & $1.8 \mathrm{E}-02$ & \pm & $2.6 \mathrm{E}-03$ & N.D. & & & $2.5 \mathrm{E}-03$ & \pm & $2.4 \mathrm{E}-03$ & $1.9 \mathrm{E}-03$ & \pm & $5.8 \mathrm{E}-04$ \\
\hline $\mathrm{PE}(16: 1 / 20: 4)-\mathrm{OOH}$ & N.D. & & & N.D. & & & N.D. & \pm & N.D. & N.D. & & & N.D. & & & N.D. & & \\
\hline $\mathrm{PE}(18: 1 / 20: 4)$ & $2.3 \mathrm{E}+01$ & \pm & $2.1 E+00$ & $2.3 \mathrm{E}+01$ & \pm & $1.1 \mathrm{E}+00$ & $2.3 E+01$ & \pm & $1.1 \mathrm{E}+00$ & $2.5 \mathrm{E}+01$ & \pm & $1.8 \mathrm{E}+00$ & $2.4 \mathrm{E}+01$ & \pm & $5.8 \mathrm{E}-01$ & $2.3 \mathrm{E}+01$ & \pm & $1.1 \mathrm{E}+00$ \\
\hline $\mathrm{PE}(18: 1 / 20: 4)-\mathrm{OH}$ & $2.6 \mathrm{E}-01$ & \pm & $5.4 \mathrm{E}-02$ & 2.3E-01 & \pm & $1.3 \mathrm{E}-02$ & 2.6E-01 & \pm & $1.1 \mathrm{E}-02$ & N.D. & & & $1.9 \mathrm{E}-01$ & \pm & $2.1 \mathrm{E}-02$ & $1.4 \mathrm{E}-01$ & \pm & $2.8 \mathrm{E}-03$ \\
\hline $\mathrm{PE}(18: 1 / 20: 4)-\mathrm{OOH}$ & N.D. & & & 1.4E-03 & \pm & $1.5 \mathrm{E}-03$ & $8.2 \mathrm{E}-03$ & \pm & $1.7 \mathrm{E}-03$ & N.D. & & & N.D. & & & $2.7 \mathrm{E}-03$ & \pm & 2.2E-03 \\
\hline $\mathrm{PE}(22: 0 / 20: 4)$ & $2.4 \mathrm{E}-01$ & \pm & $4.8 \mathrm{E}-02$ & $2.9 \mathrm{E}-01$ & \pm & $4.5 \mathrm{E}-02$ & $3.1 \mathrm{E}-01$ & \pm & $3.2 \mathrm{E}-02$ & N.D. & & & $2.4 \mathrm{E}-01$ & \pm & $2.3 \mathrm{E}-02$ & $4.1 \mathrm{E}-01$ & \pm & $5.2 \mathrm{E}-03$ \\
\hline $\mathrm{PE}(22: 0 / 20: 4)-\mathrm{OOH}$ & N.D. & & & 7.7E-04 & \pm & $2.9 \mathrm{E}-04$ & $7.5 \mathrm{E}-04$ & \pm & $8.0 \mathrm{E}-04$ & N.D. & & & N.D. & & & N.D. & & \\
\hline $\mathrm{PE}(18: 0 / 22: 4)$ & $3.0 E+00$ & \pm & $2.8 \mathrm{E}-01$ & $3.0 E+00$ & \pm & $1.2 \mathrm{E}-01$ & $3.7 E+00$ & \pm & $1.2 \mathrm{E}-01$ & $4.8 \mathrm{E}+00$ & \pm & $8.1 \mathrm{E}-01$ & $3.6 \mathrm{E}+00$ & \pm & $3.0 \mathrm{E}-02$ & $3.4 \mathrm{E}+00$ & \pm & $1.6 \mathrm{E}-01$ \\
\hline $\mathrm{PE}(18: 0 / 22: 4)-\mathrm{OOH}$ & N.D. & & & N.D. & & & $1.9 \mathrm{E}-03$ & \pm & $1.0 \mathrm{E}-03$ & $2.8 \mathrm{E}-02$ & \pm & $4.8 \mathrm{E}-02$ & $1.1 \mathrm{E}-02$ & \pm & $2.9 \mathrm{E}-03$ & $5.9 \mathrm{E}-04$ & \pm & $7.9 \mathrm{E}-05$ \\
\hline $\operatorname{PE}(18: 1 / 22: 6)$ & $1.5 \mathrm{E}+00$ & \pm & $2.2 \mathrm{E}-02$ & $1.5 \mathrm{E}+00$ & \pm & $6.8 \mathrm{E}-02$ & $1.5 \mathrm{E}+00$ & \pm & $6.5 \mathrm{E}-02$ & $9.6 \mathrm{E}-01$ & \pm & 3.3E-01 & $1.9 \mathrm{E}+00$ & \pm & $1.1 \mathrm{E}-01$ & $1.7 \mathrm{E}+00$ & \pm & $5.3 \mathrm{E}-02$ \\
\hline $\mathrm{PE}(18: 1 / 22: 6)-\mathrm{OH}$ & $5.7 \mathrm{E}-03$ & \pm & $1.8 \mathrm{E}-03$ & $1.5 \mathrm{E}-02$ & \pm & $5.0 \mathrm{E}-03$ & $1.1 \mathrm{E}-02$ & \pm & $1.3 \mathrm{E}-03$ & N.D. & & & $3.0 \mathrm{E}-03$ & \pm & $2.0 \mathrm{E}-03$ & $3.8 \mathrm{E}-03$ & \pm & $1.3 \mathrm{E}-03$ \\
\hline $\mathrm{PE}(\mathrm{P}-16: 0 / 20: 4)$ & $1.3 \mathrm{E}+01$ & \pm & $1.9 \mathrm{E}-01$ & $1.2 \mathrm{E}+01$ & \pm & $2.6 \mathrm{E}-01$ & $1.1 \mathrm{E}+01$ & \pm & 7.7E-01 & $2.0 \mathrm{E}+01$ & \pm & $1.9 \mathrm{E}+00$ & $1.4 \mathrm{E}+01$ & \pm & 7.3E-01 & $1.6 \mathrm{E}+01$ & \pm & $6.4 \mathrm{E}-01$ \\
\hline $\mathrm{PE}(\mathrm{P}-16: 0 / 20: 5)$ & $1.5 \mathrm{E}+00$ & \pm & $1.8 \mathrm{E}-01$ & $1.3 \mathrm{E}+00$ & \pm & $6.3 \mathrm{E}-02$ & $1.1 \mathrm{E}+00$ & \pm & $2.1 \mathrm{E}-02$ & $1.2 \mathrm{E}+00$ & \pm & $2.0 \mathrm{E}-01$ & $1.5 \mathrm{E}+00$ & \pm & $4.3 \mathrm{E}-02$ & $2.8 \mathrm{E}+00$ & \pm & $1.4 \mathrm{E}-02$ \\
\hline $\mathrm{PE}(\mathrm{P}-16: 0 / 20: 5)-\mathrm{OH}$ & $1.1 \mathrm{E}+00$ & \pm & $5.0 \mathrm{E}-02$ & $1.2 E+00$ & \pm & $3.5 \mathrm{E}-02$ & $9.9 \mathrm{E}-01$ & \pm & $6.5 \mathrm{E}-02$ & $6.9 \mathrm{E}-01$ & \pm & $2.2 \mathrm{E}-01$ & $1.1 \mathrm{E}+00$ & \pm & $5.3 \mathrm{E}-02$ & $1.3 E+00$ & \pm & $6.5 \mathrm{E}-02$ \\
\hline $\mathrm{PE}(\mathrm{P}-16: 0 / 20: 5)-\mathrm{OOH}$ & N.D. & & & $1.7 \mathrm{E}-03$ & \pm & $6.4 \mathrm{E}-04$ & $1.8 \mathrm{E}-02$ & \pm & $2.1 \mathrm{E}-03$ & N.D. & & & $3.6 \mathrm{E}-03$ & \pm & $3.1 \mathrm{E}-03$ & $2.1 \mathrm{E}-03$ & \pm & $9.0 \mathrm{E}-04$ \\
\hline$P E(P-16: 0 / 22: 6)$ & $3.3 \mathrm{E}+00$ & \pm & $2.6 \mathrm{E}-01$ & $2.9 \mathrm{E}+00$ & \pm & $1.6 \mathrm{E}-01$ & $2.4 \mathrm{E}+00$ & \pm & $3.0 \mathrm{E}-02$ & $2.8 \mathrm{E}+00$ & \pm & $3.6 \mathrm{E}-01$ & $2.9 \mathrm{E}+00$ & \pm & $1.0 \mathrm{E}-01$ & $4.7 \mathrm{E}+00$ & \pm & $2.1 \mathrm{E}-01$ \\
\hline $\mathrm{PE}(\mathrm{P}-16: 0 / 22: 6)-\mathrm{OH}$ & 1.1E-02 & \pm & 1.1E-03 & $7.0 \mathrm{E}-02$ & \pm & $9.1 \mathrm{E}-03$ & $8.7 \mathrm{E}-02$ & \pm & $1.4 \mathrm{E}-02$ & N.D. & & & 4.0E-02 & \pm & $1.0 \mathrm{E}-02$ & $3.7 \mathrm{E}-02$ & \pm & $1.1 \mathrm{E}-02$ \\
\hline $\mathrm{PE}(\mathrm{P}-16: 0 / 22: 6)-\mathrm{OOH}$ & $9.0 \mathrm{E}-03$ & \pm & $8.7 E-04$ & $5.2 \mathrm{E}-02$ & \pm & $2.5 \mathrm{E}-03$ & 7.1E-02 & \pm & $6.8 \mathrm{E}-03$ & N.D. & & & $3.3 \mathrm{E}-02$ & \pm & $6.4 \mathrm{E}-03$ & $2.8 \mathrm{E}-02$ & \pm & $5.0 \mathrm{E}-03$ \\
\hline $\operatorname{PE}(\mathrm{P}-18: 0 / 18: 2)$ & $1.1 \mathrm{E}+00$ & \pm & $3.3 \mathrm{E}-01$ & $1.4 \mathrm{E}+00$ & \pm & $1.0 \mathrm{E}-01$ & $1.4 \mathrm{E}+00$ & \pm & $1.2 \mathrm{E}-01$ & $1.4 \mathrm{E}+00$ & \pm & 2.1E-01 & $1.4 \mathrm{E}+00$ & \pm & $1.9 \mathrm{E}-01$ & $2.1 \mathrm{E}+00$ & \pm & $5.4 \mathrm{E}-02$ \\
\hline $\mathrm{PE}(\mathrm{P}-18: 0 / 18: 2)-\mathrm{OOH}$ & $2.6 \mathrm{E}-02$ & \pm & $1.3 \mathrm{E}-02$ & $2.8 \mathrm{E}-02$ & \pm & $1.0 \mathrm{E}-02$ & 4.5E-02 & \pm & $1.7 \mathrm{E}-02$ & 1.1E-02 & \pm & $1.9 \mathrm{E}-02$ & $2.1 \mathrm{E}-02$ & \pm & $9.7 \mathrm{E}-03$ & $2.2 \mathrm{E}-02$ & \pm & $6.3 \mathrm{E}-03$ \\
\hline $\mathrm{PE}(\mathrm{P}-18: 0 / 20: 3)$ & 1.6E-01 & \pm & $1.3 \mathrm{E}-01$ & 2.7E-01 & \pm & $1.0 \mathrm{E}-01$ & 4.3E-01 & \pm & $8.8 \mathrm{E}-02$ & 3.5E-01 & \pm & $1.9 \mathrm{E}-01$ & $2.4 \mathrm{E}-01$ & \pm & $8.2 \mathrm{E}-02$ & $1.0 \mathrm{E}+00$ & \pm & 8.9E-02 \\
\hline $\mathrm{PE}(\mathrm{P}-18: 0 / 20: 3)-\mathrm{OH}$ & $6.8 \mathrm{E}-01$ & \pm & $2.8 \mathrm{E}-02$ & $1.7 \mathrm{E}+00$ & \pm & $1.8 \mathrm{E}-01$ & $2.2 E+00$ & \pm & $1.6 \mathrm{E}-01$ & $8.2 \mathrm{E}-01$ & \pm & $5.3 \mathrm{E}-01$ & $1.2 \mathrm{E}+00$ & \pm & $1.6 \mathrm{E}-01$ & $1.9 \mathrm{E}+00$ & \pm & $4.9 \mathrm{E}-02$ \\
\hline $\mathrm{PE}(\mathrm{P}-18: 0 / 20: 3)-\mathrm{OOH}$ & $6.1 \mathrm{E}-02$ & \pm & $1.9 \mathrm{E}-02$ & $3.5 \mathrm{E}-02$ & \pm & $9.2 \mathrm{E}-03$ & $1.7 \mathrm{E}-02$ & \pm & $2.6 \mathrm{E}-03$ & N.D. & & & 7.5E-04 & \pm & $1.3 \mathrm{E}-03$ & $3.6 \mathrm{E}-03$ & \pm & $1.5 \mathrm{E}-03$ \\
\hline $\operatorname{PE}(\mathrm{P}-18: 0 / 20: 4)$ & $2.3 E+01$ & \pm & $1.2 \mathrm{E}+00$ & $2.1 E+01$ & \pm & $5.2 \mathrm{E}-01$ & $2.0 \mathrm{E}+01$ & \pm & $1.5 \mathrm{E}+00$ & $3.1 \mathrm{E}+01$ & \pm & $2.3 E+00$ & $2.6 \mathrm{E}+01$ & \pm & $1.2 \mathrm{E}+00$ & $2.6 \mathrm{E}+01$ & \pm & $2.1 \mathrm{E}+00$ \\
\hline
\end{tabular}




\begin{tabular}{|c|c|c|c|c|c|c|c|c|c|c|c|c|c|c|c|c|c|c|}
\hline \multirow{2}{*}{$\begin{array}{l}\text { Lipids } \\
\mathrm{PE}(\mathrm{P}-18: 0 / 20: 4)-\mathrm{OH}\end{array}$} & \multicolumn{3}{|c|}{ Control } & \multicolumn{3}{|c|}{ NAO+Light $0.5 \mathrm{~h}$} & \multicolumn{3}{|c|}{ NAO+Light $6 \mathrm{~h}$} & \multicolumn{3}{|c|}{ NAO+Light 48h } & \multicolumn{3}{|c|}{$\mathrm{NAO}+$ Light+FCCP $0.5 \mathrm{~h}$} & \multicolumn{3}{|c|}{$\mathrm{NAO}+$ Light+FCCP 48h } \\
\hline & $1.6 \mathrm{E}-01$ & \pm & $4.0 \mathrm{E}-02$ & $2.5 \mathrm{E}-01$ & \pm & $5.4 \mathrm{E}-02$ & $2.7 \mathrm{E}-01$ & \pm & $9.7 \mathrm{E}-03$ & $5.8 \mathrm{E}-02$ & \pm & $1.3 \mathrm{E}-02$ & $4.9 \mathrm{E}-02$ & \pm & $1.9 \mathrm{E}-02$ & $9.6 \mathrm{E}-02$ & \pm & $2.2 \mathrm{E}-02$ \\
\hline $\mathrm{PE}(\mathrm{P}-18: 0 / 20: 4)-\mathrm{OOH}$ & $1.2 \mathrm{E}-01$ & \pm & $1.7 \mathrm{E}-02$ & $2.0 \mathrm{E}-01$ & \pm & $8.5 \mathrm{E}-03$ & $2.1 \mathrm{E}-01$ & \pm & $1.1 \mathrm{E}-02$ & $4.8 \mathrm{E}-02$ & \pm & $2.3 \mathrm{E}-02$ & $4.3 \mathrm{E}-02$ & \pm & $1.9 \mathrm{E}-02$ & $7.8 \mathrm{E}-02$ & \pm & $1.4 \mathrm{E}-02$ \\
\hline$P E(P-18: 0 / 20: 5)$ & $1.4 \mathrm{E}+01$ & \pm & $8.5 \mathrm{E}-01$ & $1.4 \mathrm{E}+01$ & \pm & $5.3 \mathrm{E}-01$ & $1.4 \mathrm{E}+01$ & \pm & $1.3 \mathrm{E}-01$ & $2.1 \mathrm{E}+01$ & \pm & $1.8 \mathrm{E}+00$ & $1.6 \mathrm{E}+01$ & \pm & $1.8 \mathrm{E}-01$ & $1.5 \mathrm{E}+01$ & \pm & 3.1E-01 \\
\hline $\mathrm{PE}(\mathrm{P}-18: 0 / 20: 5)-\mathrm{OH}$ & $2.9 \mathrm{E}-01$ & \pm & $6.2 \mathrm{E}-02$ & $2.3 \mathrm{E}-01$ & \pm & $4.2 \mathrm{E}-02$ & $2.6 \mathrm{E}-01$ & \pm & $3.7 \mathrm{E}-02$ & N.D. & & & $2.5 \mathrm{E}-01$ & \pm & $4.1 \mathrm{E}-02$ & 1.7E-01 & \pm & 1.4E-02 \\
\hline $\mathrm{PE}(\mathrm{P}-18: 0 / 20: 5)-\mathrm{OOH}$ & $2.5 \mathrm{E}-01$ & \pm & $4.0 \mathrm{E}-02$ & $1.9 \mathrm{E}-01$ & \pm & 7.1E-03 & 2.2E-01 & \pm & $3.0 \mathrm{E}-02$ & N.D. & & & $2.0 \mathrm{E}-01$ & \pm & $2.9 \mathrm{E}-02$ & 1.3E-01 & \pm & 1.1E-02 \\
\hline $\mathrm{PE}(\mathrm{P}-18: 0 / 22: 4)$ & $7.6 \mathrm{E}+00$ & \pm & $1.0 \mathrm{E}+00$ & $6.4 \mathrm{E}+00$ & \pm & 4.3E-01 & $7.1 E+00$ & \pm & $3.1 \mathrm{E}-01$ & $8.3 E+00$ & \pm & $1.5 \mathrm{E}-01$ & $7.8 \mathrm{E}+00$ & \pm & $5.4 \mathrm{E}-01$ & $6.9 E+00$ & \pm & $2.0 \mathrm{E}-01$ \\
\hline $\mathrm{PE}(\mathrm{P}-18: 0 / 22: 4)-\mathrm{OH}$ & $2.3 \mathrm{E}-03$ & \pm & $3.9 \mathrm{E}-03$ & $2.5 \mathrm{E}-03$ & \pm & $1.8 \mathrm{E}-03$ & $1.3 \mathrm{E}-02$ & \pm & $7.0 \mathrm{E}-03$ & $1.6 \mathrm{E}-01$ & \pm & $6.1 \mathrm{E}-02$ & $2.1 \mathrm{E}-03$ & \pm & $1.9 \mathrm{E}-03$ & 4.4E-03 & \pm & $1.9 \mathrm{E}-03$ \\
\hline $\mathrm{PE}(\mathrm{P}-18: 0 / 22: 4)-\mathrm{OOH}$ & $1.5 \mathrm{E}-03$ & \pm & $2.7 \mathrm{E}-03$ & $1.8 \mathrm{E}-03$ & \pm & $1.1 \mathrm{E}-03$ & $8.8 \mathrm{E}-03$ & \pm & $3.3 \mathrm{E}-03$ & $1.3 \mathrm{E}-01$ & \pm & $6.4 \mathrm{E}-02$ & $1.5 \mathrm{E}-03$ & \pm & $1.4 \mathrm{E}-03$ & $3.5 \mathrm{E}-03$ & \pm & $8.6 \mathrm{E}-04$ \\
\hline $\mathrm{PE}(\mathrm{P}-18: 0 / 22: 6)$ & $5.6 \mathrm{E}+00$ & \pm & $6.1 \mathrm{E}-01$ & $4.9 \mathrm{E}+00$ & \pm & $3.6 \mathrm{E}-01$ & $4.2 E+00$ & \pm & $3.5 \mathrm{E}-02$ & $4.2 E+00$ & \pm & $3.7 \mathrm{E}-01$ & $5.0 \mathrm{E}+00$ & \pm & $2.8 \mathrm{E}-01$ & $5.4 \mathrm{E}+00$ & \pm & $1.9 \mathrm{E}-01$ \\
\hline $\mathrm{PE}(\mathrm{P}-18: 0 / 22: 6)-\mathrm{OH}$ & $3.9 \mathrm{E}-01$ & \pm & $3.1 \mathrm{E}-02$ & $1.5 \mathrm{E}-01$ & \pm & $1.5 \mathrm{E}-02$ & $1.1 \mathrm{E}-01$ & \pm & $1.3 \mathrm{E}-02$ & N.D. & & & $5.0 \mathrm{E}-02$ & \pm & $7.6 \mathrm{E}-03$ & $5.3 \mathrm{E}-02$ & \pm & $1.3 \mathrm{E}-02$ \\
\hline $\mathrm{PE}(\mathrm{P}-18: 0 / 22: 6)-\mathrm{OOH}$ & $2.9 \mathrm{E}-01$ & \pm & $3.9 \mathrm{E}-02$ & $1.2 \mathrm{E}-01$ & \pm & $7.9 \mathrm{E}-03$ & $8.3 \mathrm{E}-02$ & \pm & $3.3 \mathrm{E}-03$ & N.D. & & & $4.1 \mathrm{E}-02$ & \pm & $9.7 \mathrm{E}-03$ & $4.2 \mathrm{E}-02$ & \pm & 4.3E-03 \\
\hline$P E(P-18: 1 / 22: 6)$ & $1.1 \mathrm{E}+00$ & \pm & $1.2 \mathrm{E}-01$ & $1.1 \mathrm{E}+00$ & \pm & $6.6 \mathrm{E}-02$ & $8.9 \mathrm{E}-01$ & \pm & 4.7E-02 & 4.3E-01 & \pm & $1.4 \mathrm{E}-01$ & $1.1 \mathrm{E}+00$ & \pm & $2.0 \mathrm{E}-02$ & $1.6 \mathrm{E}+00$ & \pm & $5.6 \mathrm{E}-02$ \\
\hline $\mathrm{PE}(\mathrm{P}-18: 1 / 22: 6)-\mathrm{OH}$ & $1.3 \mathrm{E}-03$ & \pm & $2.3 \mathrm{E}-03$ & $1.6 \mathrm{E}-03$ & \pm & $1.4 \mathrm{E}-03$ & 1.2E-02 & \pm & $2.6 \mathrm{E}-03$ & $3.4 \mathrm{E}-02$ & \pm & $6.0 \mathrm{E}-02$ & N.D. & & & N.D. & & \\
\hline $\mathrm{PE}(\mathrm{P}-20: 0 / 20: 5)$ & $1.2 \mathrm{E}+01$ & \pm & $8.6 \mathrm{E}-01$ & $1.1 \mathrm{E}+01$ & \pm & $6.5 \mathrm{E}-01$ & $9.9 E+00$ & \pm & 4.2E-01 & $1.0 \mathrm{E}+01$ & \pm & $1.0 \mathrm{E}+00$ & $1.1 \mathrm{E}+01$ & \pm & $2.4 \mathrm{E}-01$ & $8.9 E+00$ & \pm & $4.8 \mathrm{E}-01$ \\
\hline $\mathrm{PE}(\mathrm{P}-20: 0 / 20: 5)-\mathrm{OH}$ & 7.7E-01 & \pm & $8.6 \mathrm{E}-02$ & 3.5E-01 & \pm & $1.5 \mathrm{E}-02$ & $2.2 \mathrm{E}-01$ & \pm & $2.6 \mathrm{E}-02$ & 1.2E-01 & \pm & $2.3 \mathrm{E}-02$ & $1.2 \mathrm{E}-01$ & \pm & $3.2 \mathrm{E}-02$ & 1.2E-01 & \pm & 7.3E-03 \\
\hline $\mathrm{PE}(\mathrm{P}-20: 0 / 20: 5)-\mathrm{OOH}$ & $5.8 \mathrm{E}-01$ & \pm & $8.9 \mathrm{E}-03$ & $2.6 \mathrm{E}-01$ & \pm & $8.6 \mathrm{E}-03$ & $1.8 \mathrm{E}-01$ & \pm & $6.0 \mathrm{E}-03$ & $9.5 \mathrm{E}-02$ & \pm & $2.3 \mathrm{E}-02$ & $9.9 \mathrm{E}-02$ & \pm & $1.7 \mathrm{E}-02$ & $9.0 \mathrm{E}-02$ & \pm & $6.5 \mathrm{E}-03$ \\
\hline$P E(P-20: 0 / 22: 4)$ & $3.8 \mathrm{E}-01$ & \pm & $2.9 \mathrm{E}-02$ & $2.8 \mathrm{E}-01$ & \pm & 7.6E-02 & 3.0E-01 & \pm & $1.0 \mathrm{E}-01$ & N.D. & & & $3.1 \mathrm{E}-01$ & \pm & 7.9E-02 & 4.2E-01 & \pm & $8.8 \mathrm{E}-02$ \\
\hline $\mathrm{PE}(\mathrm{P}-20: 0 / 22: 4)-\mathrm{OH}$ & $2.4 \mathrm{E}-01$ & \pm & $5.1 \mathrm{E}-02$ & $2.9 \mathrm{E}-01$ & \pm & $5.3 \mathrm{E}-02$ & $3.0 \mathrm{E}-01$ & \pm & $4.2 \mathrm{E}-02$ & N.D. & & & $2.3 \mathrm{E}-01$ & \pm & $2.9 \mathrm{E}-02$ & $4.2 \mathrm{E}-01$ & \pm & $2.8 \mathrm{E}-02$ \\
\hline $\mathrm{PI}(18: 0 / 20: 4)$ & $3.3 \mathrm{E}+01$ & \pm & $1.2 \mathrm{E}+01$ & $1.5 \mathrm{E}+01$ & \pm & $4.8 \mathrm{E}-01$ & $1.9 \mathrm{E}+01$ & \pm & $8.5 E+00$ & $3.2 E+01$ & \pm & $1.3 \mathrm{E}+01$ & $5.5 \mathrm{E}+01$ & \pm & $2.3 E+01$ & $1.8 \mathrm{E}+01$ & \pm & $5.1 \mathrm{E}+00$ \\
\hline $\mathrm{PI}(18: 0 / 20: 4)-\mathrm{OH}$ & $5.6 \mathrm{E}-03$ & \pm & $8.0 \mathrm{E}-03$ & $1.4 \mathrm{E}-02$ & \pm & $5.9 \mathrm{E}-03$ & $1.2 \mathrm{E}-02$ & \pm & $2.9 \mathrm{E}-03$ & $2.3 \mathrm{E}-02$ & \pm & $1.7 \mathrm{E}-02$ & $1.8 \mathrm{E}-02$ & \pm & $6.7 \mathrm{E}-03$ & $1.5 \mathrm{E}-02$ & \pm & $3.6 \mathrm{E}-03$ \\
\hline $\mathrm{Pl}(18: 0 / 22: 6)$ & $4.0 \mathrm{E}-01$ & \pm & $5.8 \mathrm{E}-01$ & 4.0E-01 & \pm & $4.9 \mathrm{E}-02$ & 4.1E-01 & \pm & $1.6 \mathrm{E}-01$ & $8.3 \mathrm{E}-01$ & \pm & $3.8 \mathrm{E}-01$ & $7.9 \mathrm{E}-01$ & \pm & $2.5 \mathrm{E}-01$ & $8.8 \mathrm{E}-01$ & \pm & $2.5 \mathrm{E}-01$ \\
\hline $\mathrm{PI}(18: 1 / 22: 4)$ & $6.4 \mathrm{E}-01$ & \pm & $9.1 \mathrm{E}-01$ & $9.6 \mathrm{E}-01$ & \pm & $8.7 \mathrm{E}-02$ & $9.2 \mathrm{E}-01$ & \pm & $3.2 \mathrm{E}-01$ & $1.4 \mathrm{E}+00$ & \pm & $3.4 \mathrm{E}-01$ & $2.5 \mathrm{E}+00$ & \pm & 7.2E-01 & $1.2 E+00$ & \pm & $4.0 \mathrm{E}-01$ \\
\hline $\mathrm{PI}(16: 0 / 18: 2)$ & $2.1 \mathrm{E}-01$ & \pm & $2.3 \mathrm{E}-01$ & $7.7 \mathrm{E}-02$ & \pm & 2.6E-02 & $1.0 \mathrm{E}-01$ & \pm & $6.3 \mathrm{E}-02$ & $2.0 \mathrm{E}-01$ & \pm & $1.0 \mathrm{E}-01$ & $7.2 \mathrm{E}-02$ & \pm & 4.3E-02 & 7.3E-02 & \pm & $5.2 \mathrm{E}-03$ \\
\hline $\mathrm{PI}(18: 0 / 18: 2)$ & $4.4 \mathrm{E}+00$ & \pm & $6.3 \mathrm{E}+00$ & $2.5 \mathrm{E}+00$ & \pm & 4.2E-01 & $2.4 \mathrm{E}+00$ & \pm & $6.5 \mathrm{E}-01$ & $3.1 E+00$ & \pm & 4.1E-01 & $3.4 \mathrm{E}+00$ & \pm & $1.8 \mathrm{E}+00$ & $2.5 E+00$ & \pm & 7.7E-01 \\
\hline $\mathrm{PI}(18: 1 / 18: 2)$ & $2.6 \mathrm{E}-01$ & \pm & $3.5 \mathrm{E}-01$ & $1.2 \mathrm{E}-01$ & \pm & $5.8 \mathrm{E}-02$ & 1.7E-01 & \pm & $6.6 \mathrm{E}-02$ & $2.0 \mathrm{E}-01$ & \pm & $1.2 \mathrm{E}-01$ & $5.6 \mathrm{E}-01$ & \pm & $2.6 \mathrm{E}-01$ & $1.0 \mathrm{E}-01$ & \pm & $4.0 \mathrm{E}-02$ \\
\hline $\mathrm{PI}(18: 0 / 20: 2)$ & $1.0 \mathrm{E}-01$ & \pm & $1.4 \mathrm{E}-01$ & $8.4 \mathrm{E}-02$ & \pm & $1.9 \mathrm{E}-02$ & $9.9 \mathrm{E}-02$ & \pm & $1.6 \mathrm{E}-02$ & $2.4 \mathrm{E}-01$ & \pm & $8.6 \mathrm{E}-02$ & $2.9 \mathrm{E}-01$ & \pm & $1.2 \mathrm{E}-01$ & 1.3E-01 & \pm & $5.8 \mathrm{E}-02$ \\
\hline $\mathrm{PI}(16: 0 / 20: 4)$ & $1.7 \mathrm{E}+00$ & \pm & $2.4 \mathrm{E}+00$ & $8.7 \mathrm{E}-01$ & \pm & $2.8 \mathrm{E}-01$ & $9.2 \mathrm{E}-01$ & \pm & $2.8 \mathrm{E}-01$ & $1.2 \mathrm{E}+00$ & \pm & $4.6 \mathrm{E}-01$ & $6.9 \mathrm{E}-01$ & \pm & $5.1 \mathrm{E}-01$ & 6.6E-01 & \pm & $1.3 \mathrm{E}-01$ \\
\hline $\mathrm{PI}(18: 1 / 20: 4)$ & $1.9 \mathrm{E}+00$ & \pm & $2.8 \mathrm{E}+00$ & $1.5 \mathrm{E}+00$ & \pm & $2.0 \mathrm{E}-01$ & $1.2 \mathrm{E}+00$ & \pm & $1.2 \mathrm{E}-01$ & $2.8 \mathrm{E}+00$ & \pm & $1.2 \mathrm{E}+00$ & $1.7 \mathrm{E}+00$ & \pm & $6.1 \mathrm{E}-01$ & $1.8 \mathrm{E}+00$ & \pm & 4.6E-01 \\
\hline $\mathrm{Pl}(18: 1 / 20: 5)$ & $1.5 \mathrm{E}-01$ & \pm & $2.2 \mathrm{E}-01$ & $8.9 \mathrm{E}-02$ & \pm & $4.9 \mathrm{E}-02$ & 8.7E-02 & \pm & $3.5 \mathrm{E}-02$ & $1.6 \mathrm{E}-01$ & \pm & $8.9 \mathrm{E}-02$ & $2.0 \mathrm{E}-01$ & \pm & $4.5 \mathrm{E}-02$ & $1.5 \mathrm{E}-01$ & \pm & $4.5 \mathrm{E}-02$ \\
\hline $\mathrm{PI}(18: 0 / 22: 4)$ & $3.7 \mathrm{E}-01$ & \pm & $5.1 \mathrm{E}-01$ & 4.3E-01 & \pm & $8.7 E-02$ & 4.7E-01 & \pm & 7.6E-02 & $5.6 \mathrm{E}-01$ & \pm & $1.3 \mathrm{E}-01$ & $1.3 \mathrm{E}+00$ & \pm & 3.1E-01 & $5.7 \mathrm{E}-01$ & \pm & $1.8 \mathrm{E}-01$ \\
\hline $\operatorname{PS}(16: 1 / 20: 3)$ & $2.1 \mathrm{E}+00$ & \pm & $3.6 \mathrm{E}-01$ & $2.2 \mathrm{E}+00$ & \pm & 4.5E-01 & $3.5 \mathrm{E}+00$ & \pm & 7.6E-01 & $2.1 \mathrm{E}+00$ & \pm & $8.1 \mathrm{E}-02$ & $4.0 \mathrm{E}+00$ & \pm & $3.7 \mathrm{E}-01$ & $1.3 E+00$ & \pm & $6.9 \mathrm{E}-02$ \\
\hline PS(18:0/18:2) & $2.0 \mathrm{E}-03$ & \pm & $3.4 \mathrm{E}-03$ & $1.8 \mathrm{E}-03$ & \pm & $3.2 \mathrm{E}-03$ & $6.2 \mathrm{E}-03$ & \pm & $5.5 \mathrm{E}-03$ & $6.8 \mathrm{E}-03$ & \pm & $5.0 \mathrm{E}-04$ & $2.7 \mathrm{E}-01$ & \pm & $3.7 \mathrm{E}-01$ & $4.5 E+00$ & \pm & $9.5 \mathrm{E}-01$ \\
\hline $\mathrm{PS}(18: 0 / 18: 2)-\mathrm{OH}$ & 7.6E-02 & \pm & $4.8 \mathrm{E}-02$ & $7.5 \mathrm{E}-02$ & \pm & $4.8 \mathrm{E}-02$ & $9.4 \mathrm{E}-03$ & \pm & $2.1 \mathrm{E}-03$ & $3.0 \mathrm{E}-03$ & \pm & $2.1 \mathrm{E}-04$ & $4.6 \mathrm{E}-03$ & \pm & $4.0 \mathrm{E}-03$ & $1.0 \mathrm{E}-03$ & \pm & $2.7 \mathrm{E}-04$ \\
\hline $\mathrm{PS}(18: 0 / 18: 2)-\mathrm{OOH}$ & $9.4 \mathrm{E}-03$ & \pm & 4.2E-03 & $1.0 \mathrm{E}-02$ & \pm & $5.3 \mathrm{E}-03$ & 7.1E-04 & \pm & $1.2 \mathrm{E}-03$ & N.D. & & & N.D. & & & N.D. & & \\
\hline PS(18:0/20:4) & $2.4 \mathrm{E}+01$ & \pm & $3.1 \mathrm{E}+00$ & $2.3 \mathrm{E}+01$ & \pm & $4.0 \mathrm{E}+00$ & $2.4 \mathrm{E}+01$ & \pm & $2.4 \mathrm{E}+00$ & 1.7E+01 & \pm & $4.9 \mathrm{E}-01$ & $2.7 \mathrm{E}+01$ & \pm & $8.9 \mathrm{E}-01$ & $1.4 \mathrm{E}+01$ & \pm & $5.7 \mathrm{E}-01$ \\
\hline $\mathrm{PS}(18: 0 / 20: 4)-\mathrm{OH}$ & $2.4 \mathrm{E}-01$ & \pm & $2.6 \mathrm{E}-02$ & $2.4 \mathrm{E}-01$ & \pm & $4.2 \mathrm{E}-02$ & $1.2 \mathrm{E}-02$ & \pm & $2.6 \mathrm{E}-03$ & $3.8 \mathrm{E}-02$ & \pm & $4.9 \mathrm{E}-03$ & $2.6 \mathrm{E}-02$ & \pm & $2.2 \mathrm{E}-02$ & $5.2 \mathrm{E}-03$ & \pm & $2.5 \mathrm{E}-03$ \\
\hline PS(18:1/22:4) & $6.6 \mathrm{E}-01$ & \pm & $1.9 \mathrm{E}-01$ & $6.5 \mathrm{E}-01$ & \pm & $1.9 \mathrm{E}-01$ & 4.7E-01 & \pm & 1.7E-01 & 3.5E-01 & \pm & $2.7 \mathrm{E}-02$ & $1.4 \mathrm{E}+00$ & \pm & 1.4E-01 & $4.3 E+00$ & \pm & $1.2 \mathrm{E}-01$ \\
\hline
\end{tabular}




\begin{tabular}{|c|c|c|c|c|c|c|c|c|c|c|c|c|c|c|c|c|c|c|}
\hline \multirow{2}{*}{$\begin{array}{l}\text { Lipids } \\
\text { PS(22:0/18:2) }\end{array}$} & \multicolumn{3}{|c|}{ Control } & \multicolumn{3}{|c|}{ NAO+Light $0.5 \mathrm{~h}$} & \multicolumn{3}{|c|}{ NAO+Light $6 \mathrm{~h}$} & \multicolumn{3}{|c|}{ NAO+Light $48 \mathrm{~h}$} & \multicolumn{3}{|c|}{ NAO+Light+FCCP 0.5h } & \multicolumn{3}{|c|}{ NAO+Light+FCCP 48h } \\
\hline & $2.9 \mathrm{E}-02$ & \pm & $1.0 \mathrm{E}-02$ & $2.9 \mathrm{E}-02$ & \pm & $1.2 \mathrm{E}-02$ & $1.6 \mathrm{E}-02$ & \pm & $7.9 \mathrm{E}-03$ & $1.4 \mathrm{E}-02$ & \pm & $4.8 \mathrm{E}-04$ & $1.0 \mathrm{E}-01$ & \pm & $5.4 \mathrm{E}-02$ & $6.4 \mathrm{E}-02$ & \pm & $2.4 \mathrm{E}-02$ \\
\hline $\mathrm{PS}(20: 1 / 22: 4)$ & $1.9 \mathrm{E}+00$ & \pm & $3.9 \mathrm{E}-01$ & $1.8 \mathrm{E}+00$ & \pm & $5.3 \mathrm{E}-01$ & $1.5 \mathrm{E}+00$ & \pm & $3.2 \mathrm{E}-01$ & $1.0 \mathrm{E}+00$ & \pm & $3.5 \mathrm{E}-02$ & $2.7 \mathrm{E}+00$ & \pm & $2.2 \mathrm{E}-01$ & $5.9 \mathrm{E}-01$ & \pm & $1.7 \mathrm{E}-02$ \\
\hline $\mathrm{PS}(18: 0 / 20: 2)$ & 1.4E-01 & \pm & $3.5 \mathrm{E}-02$ & $1.3 \mathrm{E}-01$ & \pm & $2.8 \mathrm{E}-02$ & $2.3 \mathrm{E}-01$ & \pm & $1.2 \mathrm{E}-02$ & $7.6 \mathrm{E}-02$ & \pm & $4.6 \mathrm{E}-03$ & 1.6E-01 & \pm & $1.4 \mathrm{E}-01$ & 1.1E-01 & \pm & $2.8 \mathrm{E}-02$ \\
\hline $\mathrm{PS}(18: 0 / 20: 2)-\mathrm{OH}$ & $4.6 \mathrm{E}-03$ & \pm & $2.6 \mathrm{E}-03$ & 4.4E-03 & \pm & $2.7 \mathrm{E}-03$ & 7.7E-04 & \pm & $1.3 \mathrm{E}-03$ & $3.6 \mathrm{E}-03$ & \pm & $2.1 \mathrm{E}-04$ & N.D. & & & $5.4 \mathrm{E}-04$ & \pm & 4.7E-04 \\
\hline $\mathrm{PS}(18: 0 / 20: 2)-\mathrm{OOH}$ & $5.6 \mathrm{E}-04$ & \pm & $9.6 \mathrm{E}-04$ & $5.6 \mathrm{E}-04$ & \pm & $9.6 \mathrm{E}-04$ & $9.1 \mathrm{E}-04$ & \pm & $1.6 \mathrm{E}-03$ & $3.5 \mathrm{E}-03$ & \pm & $1.8 \mathrm{E}-04$ & $2.0 \mathrm{E}-03$ & \pm & $3.4 \mathrm{E}-03$ & $2.1 \mathrm{E}-03$ & \pm & $1.8 \mathrm{E}-03$ \\
\hline $\mathrm{PS}(20: 2 / 22: 6)$ & $1.6 \mathrm{E}+00$ & \pm & $2.8 \mathrm{E}-01$ & $1.5 \mathrm{E}+00$ & \pm & $4.0 \mathrm{E}-01$ & $4.3 E+00$ & \pm & $5.2 \mathrm{E}-01$ & $2.4 \mathrm{E}+00$ & \pm & $7.5 \mathrm{E}-02$ & $4.1 \mathrm{E}+00$ & \pm & $2.5 \mathrm{E}-01$ & $1.5 \mathrm{E}+00$ & \pm & $9.2 \mathrm{E}-02$ \\
\hline $\mathrm{PS}(20: 3 / 20: 4)$ & $5.9 \mathrm{E}+00$ & \pm & $1.6 \mathrm{E}+00$ & $6.1 E+00$ & \pm & $1.6 \mathrm{E}+00$ & $4.7 \mathrm{E}+00$ & \pm & $1.6 \mathrm{E}-01$ & $3.7 E+00$ & \pm & $6.5 \mathrm{E}-02$ & $8.2 E+00$ & \pm & $5.8 \mathrm{E}-01$ & $2.7 \mathrm{E}+00$ & \pm & $1.5 \mathrm{E}-01$ \\
\hline PS(20:3/20:4)-OH & $6.4 \mathrm{E}-02$ & \pm & $1.4 \mathrm{E}-02$ & $6.9 \mathrm{E}-02$ & \pm & $1.3 \mathrm{E}-02$ & $9.1 \mathrm{E}-04$ & \pm & $1.6 \mathrm{E}-03$ & $1.8 \mathrm{E}-03$ & \pm & 1.8E-04 & N.D. & & & $6.4 \mathrm{E}-04$ & \pm & $5.5 \mathrm{E}-04$ \\
\hline $\mathrm{PS}(20: 3 / 20: 4)-\mathrm{OOH}$ & $6.8 \mathrm{E}-01$ & \pm & $6.9 \mathrm{E}-02$ & $6.5 \mathrm{E}-01$ & \pm & $1.1 \mathrm{E}-01$ & 8.2E-01 & \pm & $1.2 \mathrm{E}-01$ & $5.6 \mathrm{E}-01$ & \pm & $9.5 \mathrm{E}-03$ & $8.1 \mathrm{E}-01$ & \pm & $1.2 \mathrm{E}-01$ & $2.5 \mathrm{E}-01$ & \pm & $2.9 \mathrm{E}-02$ \\
\hline $\mathrm{PS}(20: 3 / 22: 4)$ & $2.4 \mathrm{E}+00$ & \pm & $4.8 \mathrm{E}-01$ & $2.3 \mathrm{E}+00$ & \pm & $5.8 \mathrm{E}-01$ & $3.5 \mathrm{E}+00$ & \pm & $5.3 \mathrm{E}-01$ & $2.3 \mathrm{E}+00$ & \pm & $6.6 \mathrm{E}-02$ & $4.9 \mathrm{E}+00$ & \pm & $5.7 \mathrm{E}-01$ & $1.3 \mathrm{E}+00$ & \pm & $4.6 \mathrm{E}-02$ \\
\hline $\mathrm{PS}(20: 3 / 22: 6)$ & $1.6 \mathrm{E}+00$ & \pm & $3.2 \mathrm{E}-01$ & $1.6 \mathrm{E}+00$ & \pm & $2.2 \mathrm{E}-01$ & $3.2 E+00$ & \pm & 7.4E-01 & $1.8 \mathrm{E}+00$ & \pm & $5.5 \mathrm{E}-02$ & $2.4 \mathrm{E}+00$ & \pm & $3.7 \mathrm{E}-01$ & $1.0 \mathrm{E}+00$ & \pm & $7.3 \mathrm{E}-02$ \\
\hline $\operatorname{PS}(18: 1 / 20: 4)$ & $5.1 E+00$ & \pm & $1.1 E+00$ & $4.9 \mathrm{E}+00$ & \pm & $1.4 \mathrm{E}+00$ & $5.5 \mathrm{E}+00$ & \pm & 7.7E-01 & $3.7 \mathrm{E}+00$ & \pm & $6.4 \mathrm{E}-02$ & $7.5 E+00$ & \pm & $7.8 \mathrm{E}-01$ & $2.6 \mathrm{E}+00$ & \pm & $9.9 \mathrm{E}-02$ \\
\hline PS(18:1/20:4)-OOH & $1.5 \mathrm{E}-02$ & \pm & $2.3 \mathrm{E}-03$ & $1.4 \mathrm{E}-02$ & \pm & $1.2 \mathrm{E}-03$ & $2.0 \mathrm{E}-03$ & \pm & 4.6E-04 & N.D. & & & N.D. & & & $8.6 \mathrm{E}-04$ & \pm & $7.8 \mathrm{E}-04$ \\
\hline PS(22:1/20:5) & $6.4 \mathrm{E}-01$ & \pm & $1.4 \mathrm{E}-01$ & $6.3 \mathrm{E}-01$ & \pm & $1.3 \mathrm{E}-01$ & $7.9 \mathrm{E}-01$ & \pm & 1.6E-01 & $5.2 \mathrm{E}-01$ & \pm & $4.0 \mathrm{E}-02$ & $1.3 E+00$ & \pm & $1.6 \mathrm{E}-01$ & $3.4 \mathrm{E}-01$ & \pm & $4.6 \mathrm{E}-02$ \\
\hline$P S(18: 0 / 22: 4)$ & 7.3E-01 & \pm & $6.9 \mathrm{E}-01$ & 7.1E-01 & \pm & $6.6 \mathrm{E}-01$ & $9.7 \mathrm{E}-01$ & \pm & $9.9 \mathrm{E}-01$ & $2.0 \mathrm{E}+00$ & \pm & $4.9 \mathrm{E}-02$ & $1.7 \mathrm{E}+00$ & \pm & $1.2 \mathrm{E}+00$ & $4.8 \mathrm{E}+00$ & \pm & $3.6 \mathrm{E}-01$ \\
\hline
\end{tabular}




\section{Supporting information table S2}

Quantification of phospholipid levels in WT and Cardiolipin Synthase (CLS) knockdown HeLa cells

\begin{tabular}{lll}
\hline Phospholipid & pmol/nmol total phospholipid phosphorous \\
\cline { 2 - 3 } & WT & CLS knockdown \\
\hline CL & $20.8 \pm 1.4$ & $9.2 \pm 1.5^{*}$ \\
PG & $3.3 \pm 0.5$ & $5.2 \pm 0.1^{*}$ \\
PE & $241.4 \pm 21.6$ & $253.8 \pm 18.9$ \\
PC & $535.5 \pm 31.9$ & $547.7 \pm 42.7$ \\
PS & $63.7 \pm 5.4$ & $65.4 \pm 3.9$ \\
PI & $79.2 \pm 11.0$ & $74.1 \pm 7.1$ \\
Sph & $58.0 \pm 6.3$ & $49.8 \pm 15.0$ \\
\hline
\end{tabular}

Data presented are means $\pm S D(n=3)$

${ }^{*} p<0.01$ vs WT HeLa cells

CL: cardiolipin; PG: phosphatidylglycerol; PE: phosphatidylethanolamine; PC:

phosphatidylcholine; PS: phosphatidylserine; PI: phosphatidylinositol; Sph:

sphingomyelin.

Quoted and modified from Free radical biology \& medicine 44, 1935-1944 ${ }^{1}$ 


\section{Supporting information figure S1}

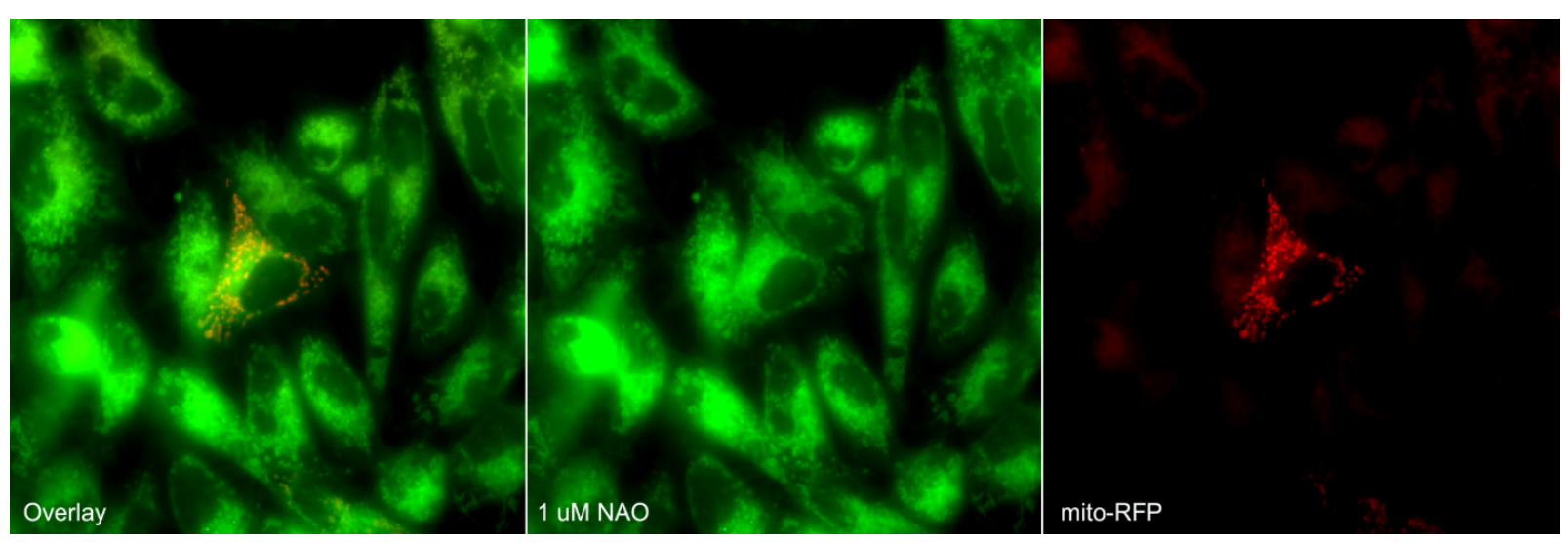

At a high concentration of $1 \mu \mathrm{M}, \mathrm{NAO}$ diffused into extra-mitochondrial

compartments (30 min incubation). Mitochondria were visualized using the mFAP technology (in red). 


\section{Supporting information figure S2}

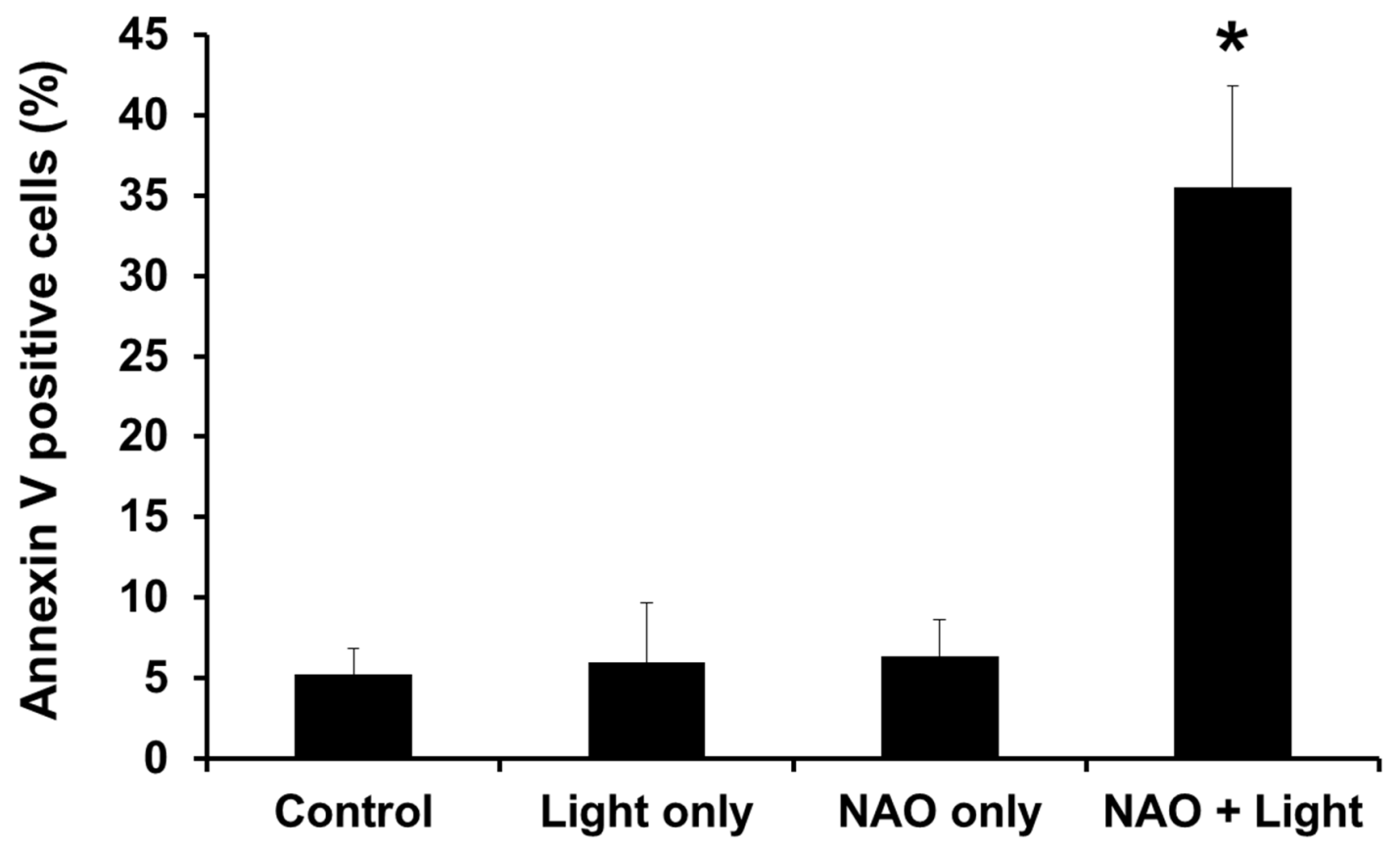

NAO facilitates photo-induced apoptosis in mouse embryonic cells (MECs).

MECs were treated with $100 \mathrm{nM}$ NAO for $30 \mathrm{~min}$, washed by medium and exposed to light at the intensity of $11.4 \mathrm{~W} / \mathrm{cm}^{2}$ for $30 \mathrm{~min}$. At $24 \mathrm{~h}$ after treatment, cells were collected for analysis of phosphatidylserine (PS) externalization indicated by Annexin $V$ binding. Mean $\pm \mathrm{SD}(\mathrm{n}=3) .{ }^{*} p<0.05$ vs. control, NAO only, and light only groups. 


\section{Supporting information figure S3}
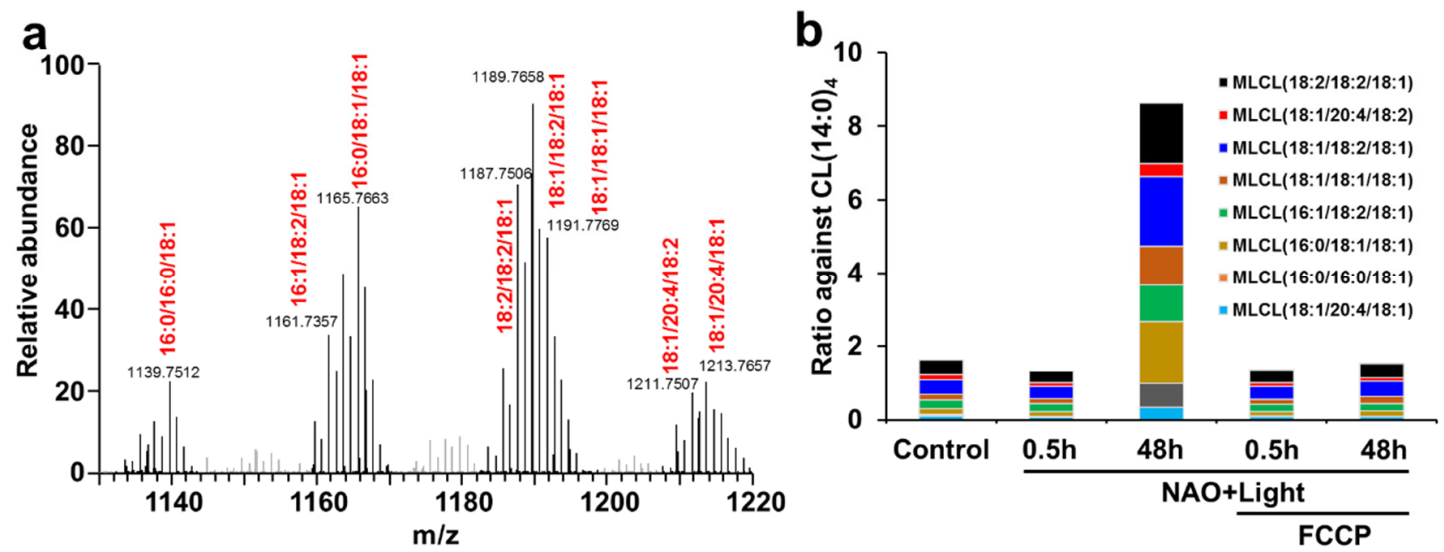

Monolyso-cardiolipin (MLCL) increased 48 hours after NAO+Light treatment.

a. Eight major species of MLCLs (indicated by red) were identified by accurate $\mathrm{m} / \mathrm{z}$ value ( $<5 \mathrm{ppm})$ and its corresponding MS/MS fragments. b. Relative quantitation was achieved by comparing to $\mathrm{CL}(14: 0)_{4}$, showing the amount of each MLCL species and total amount in stacked bar-plot. 


\section{Supporting information figure $\mathbf{S 4}$}

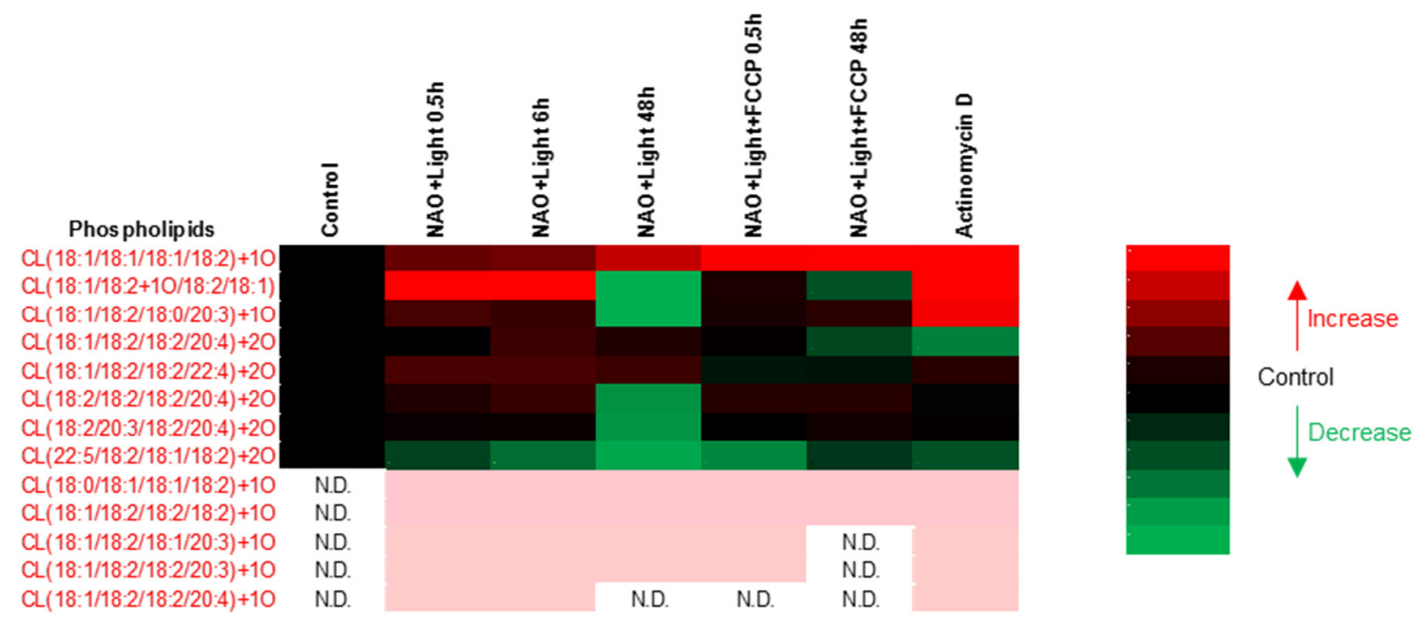

Heat map (fold-change) of oxygenated CL species formed during NAO plus lightinduced apoptosis and actinomycin D -induced apoptosis. HeLa cells were treated with $100 \mathrm{nM}$ actinomycin $\mathrm{D}$ for $18 \mathrm{~h}$; this resulted in $38 \%$ apoptotic cells indicated by externalization of PS. The analysis was performed with three replicates and the color of each box represents the relative content of the corresponding CL species; color coding - black for no change, red for increased content, and green for decreased content). For those CLs that were not detected (N.D.) in control, no color was applied. 


\section{Supporting information figure S5}

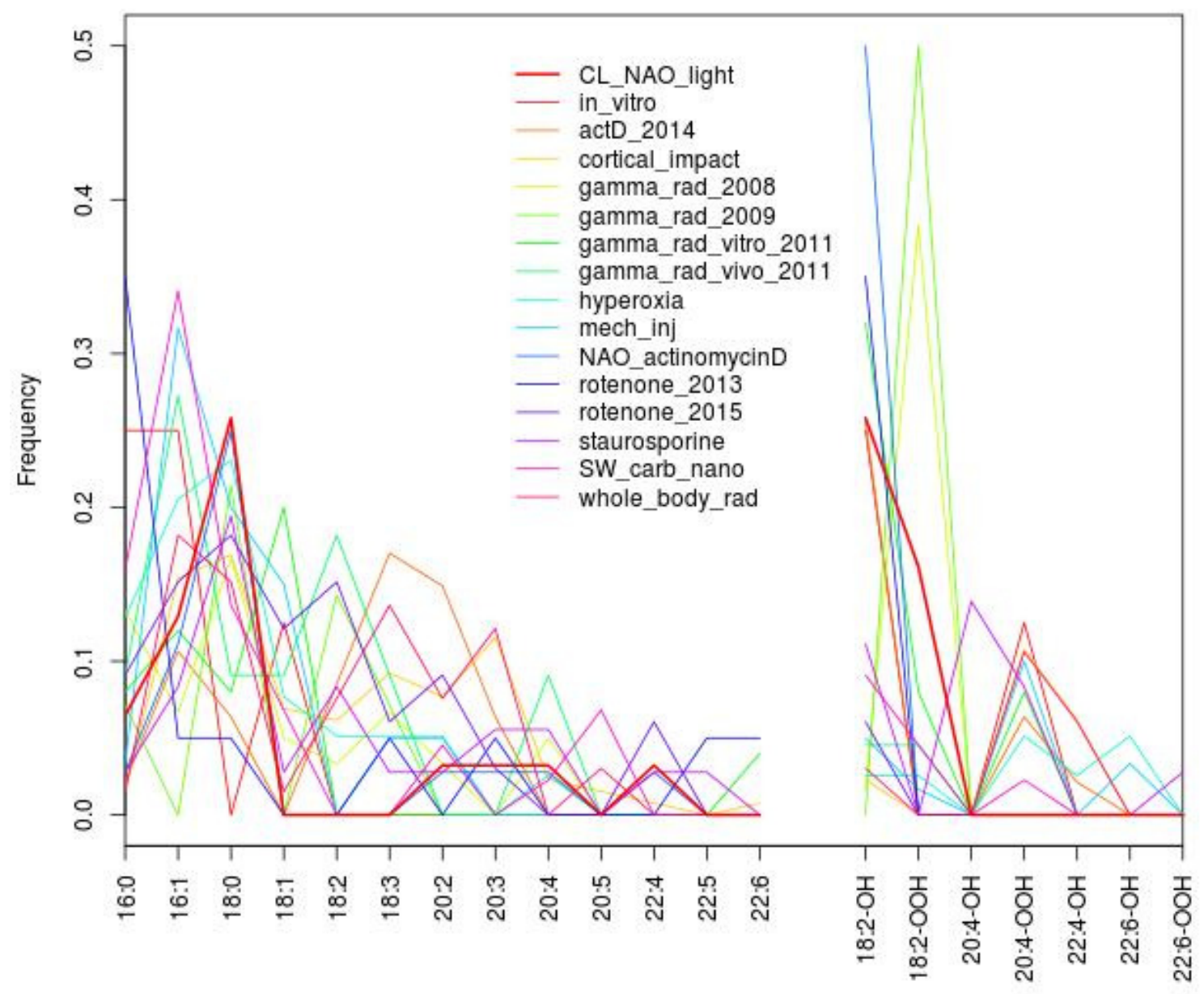

Unigram analysis of all CL acyl chains from the current study and other previous ones. Each line represents a different experiment. The extracted n-grams (single acyl chains in the observed CL molecules) are shown on the x-axis and their corresponding frequencies on the y-axis. N-grams containing oxygenated FA species are shown in the right end of the plot, and in Figure 5 of the main manuscript. 
Supporting information figure S6

Man

WNANWNaN

AN

Bi-gram analysis of CL acyl chains from the same datasets and details as in Supporting information figure S5.

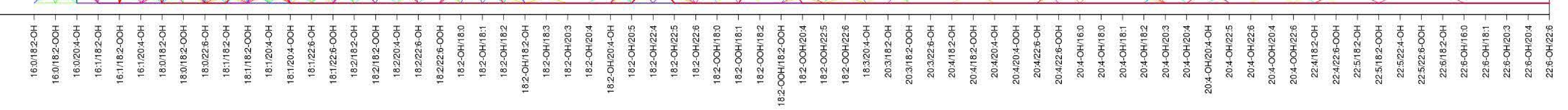




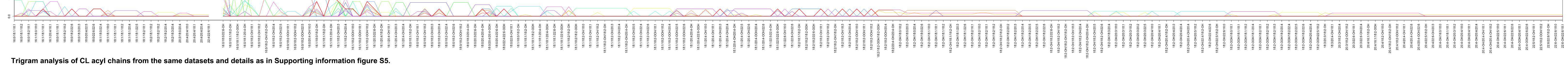




\section{Supporting information figure $\mathbf{S 9}$}

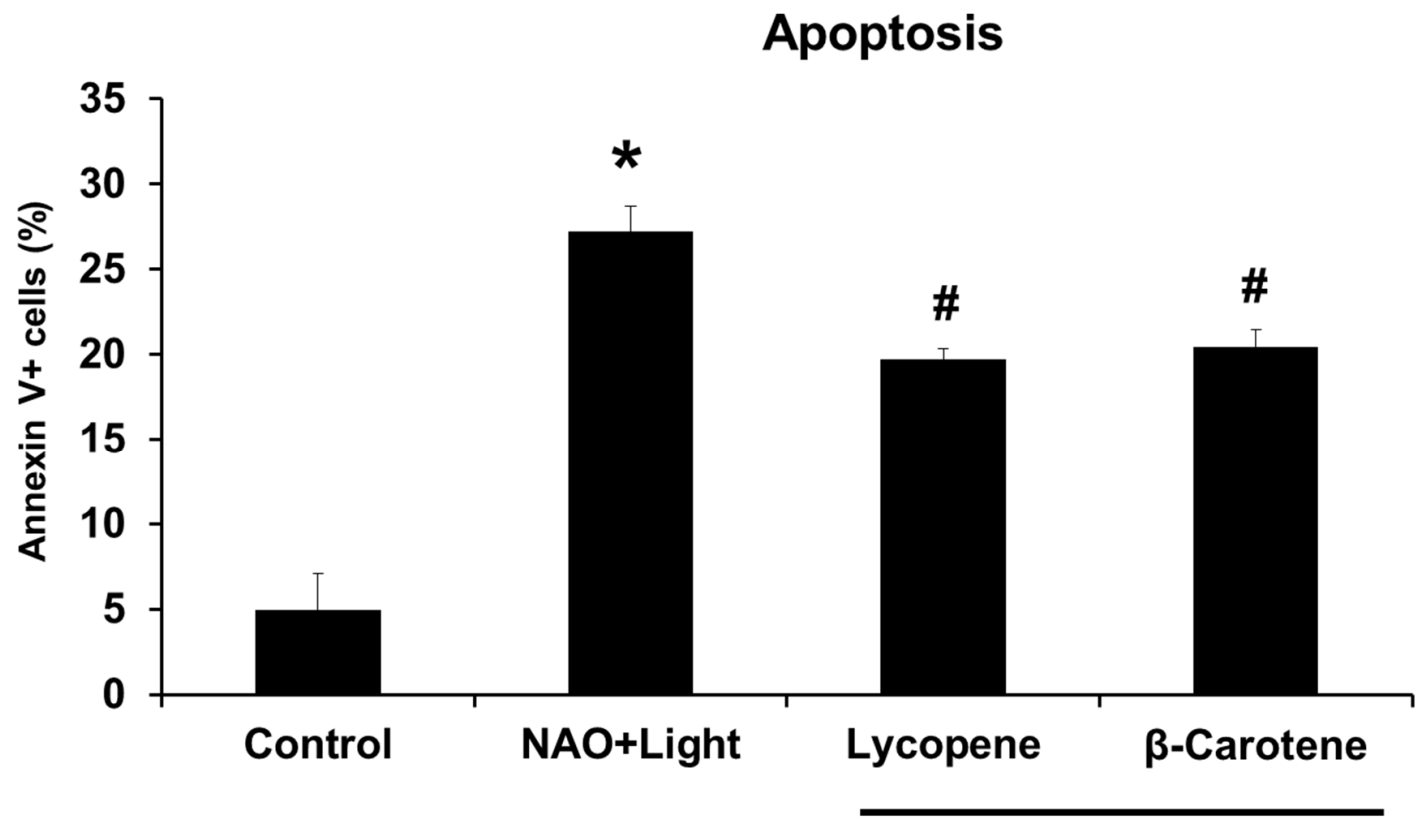

NAO + light

Singlet oxygen quenchers partially protect cells against apoptosis induced by NAO and light exposure. Cells were pre-treated with $10 \mu \mathrm{M}$ Lycopene and $10 \mu \mathrm{M} \beta$-Carotene before NAO staining and light exposure. Cells were collected for analysis of PS externalization by Annexin V binding at $24 \mathrm{~h}$ after treatments. Mean $\pm \mathrm{SD}(\mathrm{N}=3) .{ }^{*} p<0.05$ vs. non-treated controls. ${ }^{*} p<0.05$ vs. NAO and light treatments. 


\section{Supporting information figure $\mathbf{S 1 0}$}

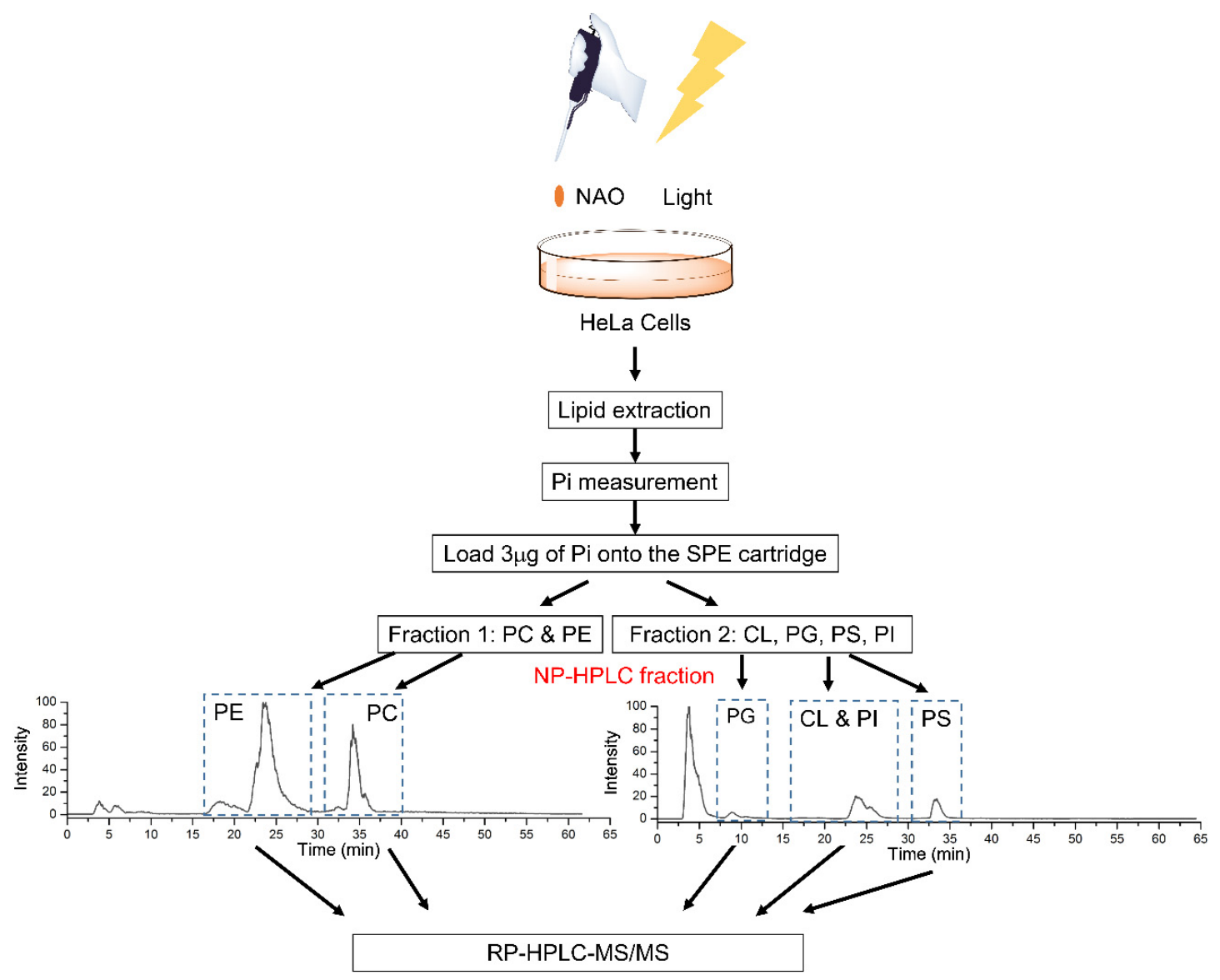

A flow-chart illustrating the LC-MS analytical protocols employed in assessments of phospholipids and their oxygenated species in HeLa cells. 


\section{Supporting information figure S11}
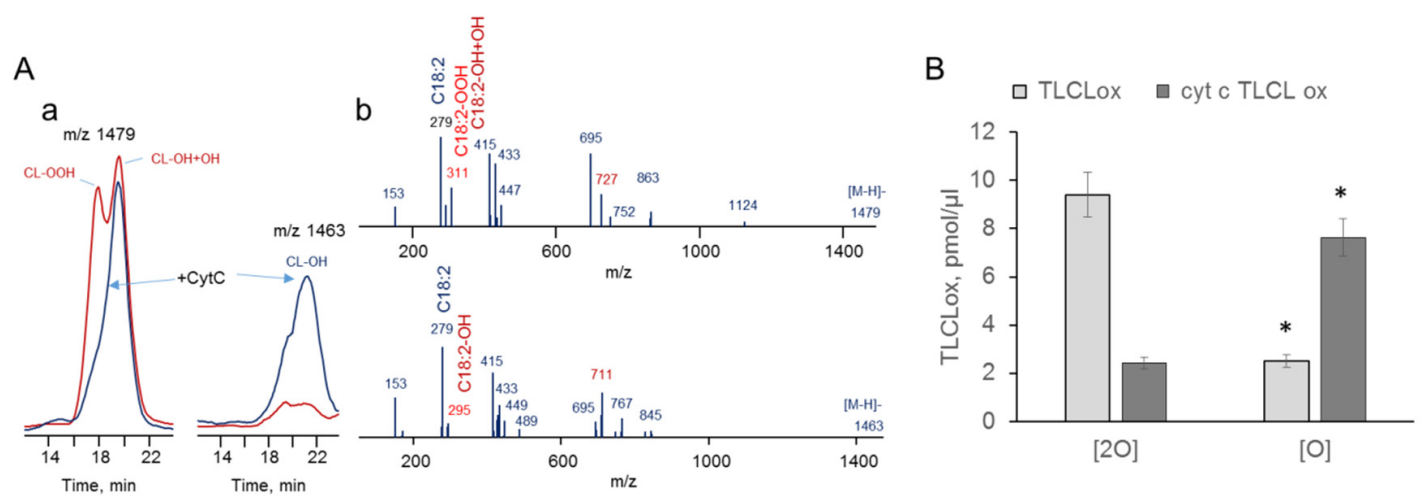

\section{LC-MS/MS analysis and quantitation of TLCL ox reduction by Cyt $C$. (A a)}

Typical profiles of singly charged TLCLox molecular species with m/z 1479 and 1463, corresponding to hydroperoxy- , hydroxy-hydroxy-TLCL and monohydroxy-TLCL ( $A$ a, curves in red color - before incubation with $C y t C$ and $A$ a, curves in dark blue color - after incubation with Cyt C, respectively). (A b) MS2 fragmentation of parent ions at m/z 1479 an 1463 resulted in formation of nonoxidized ion fragment with $\mathrm{m} / \mathrm{z} 695$ and oxidized ion fragments with $\mathrm{m} / \mathrm{z} 727$ and 711 , respectively. The major product ion with $\mathrm{m} / \mathrm{z} 279$ corresponds to C18:2. Product ions with m/z 311 (C18:2-OOH and C18:2-OH+OH) and 295 (C18:2$\mathrm{OH}$ ) were observed in the spectra after fragmentation of the molecular ion with $\mathrm{m} / \mathrm{z} 727$ and 711, respectively. (B) Quantitative assessment of the reduction of di-oxygenated cardiolipin (TLCL-OOH) to mono-oxygenated cardiolipin (TLCL$\mathrm{OH}$ ) after incubation with Cyt C. $2.5 \mu \mathrm{M}$ of $C y t C$ was incubated with liposomes containing $50 \mu \mathrm{M}$ TLCLox/DOPC in ratio (1:1) for $30 \mathrm{~min}$ in room temperature. ( ${ }^{*}$ $p<0.05$ vs. samples incubated without Cyt C). Related method was described in Supporting information methods. 


\section{Supporting information figure $\mathbf{S 1 2}$}

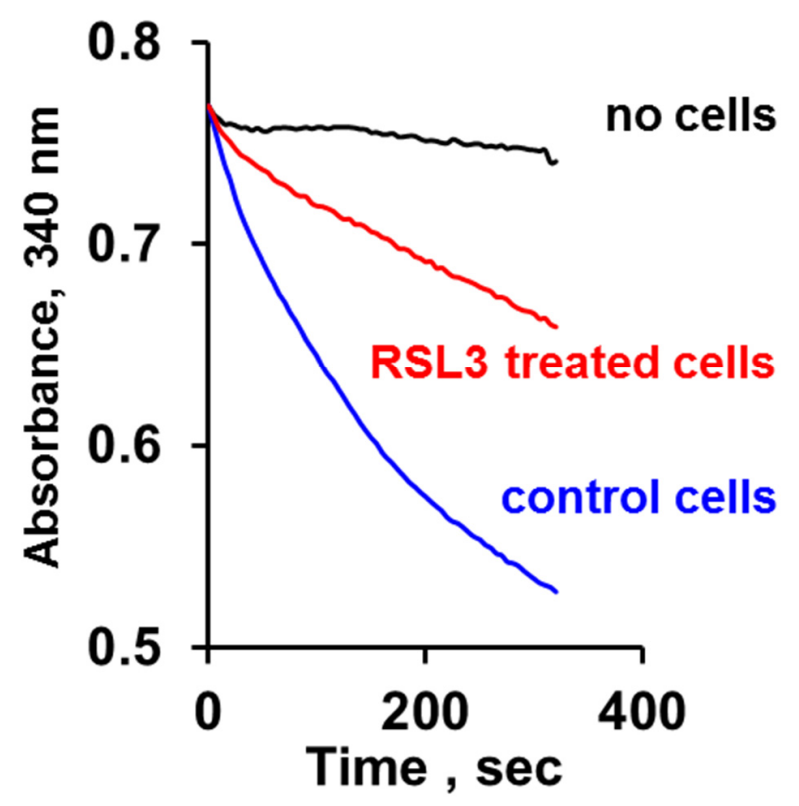

TLCL-OOH can be reduced by Gpx4 from cell homogenate. As a negative control, TLCL-OOH cannot be reduced where glutathione peroxidase $4(\mathrm{Gpx} 4)$ is inactivated by a chemical compound (100 nM RSL3 for 9 h). GPX4 activities of homogenates of MEF cells were monitored by the disappearance of NADPH absorbance at $340 \mathrm{~nm}$. Homogenates (300 $\mu \mathrm{g}$ of protein per sample) were incubated in buffer containing $0.1 \mathrm{M}$ Tris (pH8.0), $0.5 \mathrm{mM}$ EDTA, $1.25 \%$ triton $\mathrm{X}$ 100 with $50 \mu \mathrm{M}$ of TLCLox. Concentration of NADPH was $0.2 \mathrm{mM}$, concentration of glutathione was $3 \mathrm{mM}$. Concentration of glutathione peroxidase was $1 \mathrm{u} / \mathrm{ml}$. 


\section{Supplmental Materials and Methods}

\section{Materials}

MitoTracker Deep Red, tetramethylrhodamine (TMRM), and 5,5',6,6'tetrachloro1,1',3,3'-tetraethylbenzimidazolyl carbocyanine iodide (JC-1) were purchased from Invitrogen (Carlsbad, CA, USA). All the lipid standards were purchased from Avanti Polar Lipids Inc. (Alabaster, AL, USA). 10-nonylacridine orange bromide was purchased from Life Technology (Grand Island, NY, USA). All other reagents were purchased from Sigma-Aldrich unless indicated.

\section{Cell lines and cell culture conditions}

Mouse embryonic cells (MECs), HeLa cells, and cardiolipin synthase (CLS) knockdown cells were maintained in Dulbecco's Modified Eagle's Medium (DMEM) with 15\% fetal bovine serum (FBS), supplemented with $25 \mathrm{mM}$ Hepes, $50 \mathrm{mg} / \mathrm{L}$ uridine, $2 \mathrm{mM}$ glutamine, $1 \times$ nonessential amino acids, 2'mercaptoethanol, $100 \mathrm{U} / \mathrm{ml}$ penicillin, and $100 \mu \mathrm{g} / \mathrm{ml}$ streptomycin. Cells were grown in incubators with controlled temperature of $37^{\circ} \mathrm{C}, \mathrm{CO}_{2}$ of $5 \%$ and humidity of $95 \%$. Cells were harvested by trypsinization for further analysis.

\section{Phosphatidylserine externalization}

At the end of incubation, both adherent cells and floating cells in the medium were harvested and incubated with annexin V-FITC conjugate for 5 min in $1 \times$ binding buffer for the determination of phosphatidylserine (PS) externalization. 
Cells were analyzed by flow cytometry (FACScanto II, BD, NJ, USA) and data were analyzed using FlowJo software (Tree Star, Inc., Ashland, OR).

\section{Caspase activity}

Caspase activity was evaluated using caspase-Glo 3/7 kit (Promega, Madison, WI) according to the instructions provided by the supplier. Briefly, after 3 freezethaw cycles, cells were mixed with assay reagents in a 96-well white walled clear bottom plate and incubated in dark for 30-60 min. Fluorescence values were obtained from each well using a "Fusion a" universal microplate analyzer (PerkinElmer, Shelton, CT).

\section{TUNEL assay for DNA fragmentation from apoptosis}

The terminal deoxytransferase-mediated dUTP nick end-labeling (TUNEL) assay was performed as previously described ${ }^{14}$. DAPI stain was used to label all nuclei. The total number of cells indicated by DAPI staining and the number of cells undergoing apoptosis indicated by TUNEL staining were counted semiautomatically. Three random fields on each slide were counted and at least 600 cells were counted on each slide.

\section{Analysis of phospholipids and their oxygenated molecular species by Solid phase extraction (SPE)-2D-LC-MS \\ SPE method}

First, the SPE cartridge (Strata $® \mathrm{NH} 2(55 \mu \mathrm{m}, 70 \AA), 100 \mathrm{mg} / 1 \mathrm{~mL}$, purchased from Phenomenex California, USA) was preconditioned with a mixture of $7.5 \mathrm{~mL}$ 
hexane/chloroform/methanol (95:3:2; v/v/v). Then the $0.5 \mathrm{~mL}$ of lipid extract was loaded on the cartridge and washed with $15 \mathrm{~mL}$ hexane/diethyl ether/acetic acid $(80: 20: 3 ; \mathrm{v} / \mathrm{v} / \mathrm{v})$. This washing fraction, containing undesirable components such as non-polar lipids consisting of di- and triacylglycerols, waxes, and cholesterol esters, was collected as fraction 1 . Subsequently, the cartridge was eluted with 5 $\mathrm{mL}$ of chloroform/methanol $(2: 1 ; \mathrm{v} / \mathrm{v}$ ), resulting in fraction 2 (phosphatidylcholine $(P C)$ and phosphatidylethanolamine $(P E))$. Further the cartridge was eluted with $10 \mathrm{~mL}$ chloroform/methanol/28\% ammonium hydroxide $(4: 1: 0.1 ; \mathrm{v} / \mathrm{v} / \mathrm{v})$ and $5 \mathrm{~mL}$ chloroform/methanol/ammonium acetate $(4: 1: 0.2 \mathrm{M})$, thereby collecting fraction 3 (phosphatidylglycerol (PG), cardiolipin (CL), phosphatidylserine (PS) and phosphatidylinositol (PI)). Fractions 2 and 3 were dried under gentle nitrogen and re-dissolved in $15 \mu \mathrm{L}$ of $n$-propanol/hexane/water/0.5\% triethylamine (TEA)/0.01\% Formic Acid (57/43/1/0.5/0.01) with $10 \mathrm{mM}$ ammonium acetate.

\section{LC-MS/MS method}

Each fraction from SPE was further loaded onto a normal phase HPLC-MS/MS system. The column was Silica Luna $3 \mu \mathrm{m}, 150 \times 2 \mathrm{~mm}$, (Phenomenex, Torrance, CA). Solvent A consisted of $n$-propanol/hexane/water/0.5\% TEA/0.01\% Formic Acid $(57 / 43 / 1 / 0.5 / 0.01 ; \mathrm{v} / \mathrm{v} / \mathrm{v} / \mathrm{v} / \mathrm{v})$ with $10 \mathrm{mM}$ ammonium acetate. Solvent B consisted of n-propanol/hexane/water/0.5\% TEA/0.01\% Formic Acid $(57 / 43 / 8 / 0.5 / 0.01 ; \mathrm{v} / \mathrm{v} / \mathrm{v} / \mathrm{v} / \mathrm{v})$ with $10 \mathrm{mM}$ ammonium acetate. The gradient is described below (flow rate was $0.2 \mathrm{~mL} / \mathrm{min}$ unless specified): $0-1 \mathrm{~min}, 10 \% \mathrm{~B} ; 1$ 15 min, 10\%-37\%B; $15-23$ min, 37\%-40\%B; 23-25min, 40\%-100\%B, flow rate 0.2 $\mathrm{mL} / \mathrm{min}-0.225 \mathrm{~mL} / \mathrm{min} ; 25-47 \mathrm{~min}, 100 \% \mathrm{~B}$, flow rate $0.225 \mathrm{~mL} / \mathrm{min} ; 47-48 \mathrm{~min}$, 
$100 \%-10 \% \mathrm{~B}$, flow rate $0.225 \mathrm{~mL} / \mathrm{min}-0.2 \mathrm{~mL} / \mathrm{min} ; 48-70 \mathrm{~min}, 10 \% \mathrm{~B}$. Two third of the flow was diverted to a fraction collector (Spectra/Chrom CF-1 Fraction Collector, Spectrum Chromatography, Houston, TX US ) while the remainder was used for mass spectrometry (LCQDuo, Thermo-Finnigan) monitoring. Parameters for LCQDuo were as follows: spray voltage, $4.5 \mathrm{kV}$, negative mode; capillary temp, $250{ }^{\circ} \mathrm{C}$; sheath gas, 30 units. Individual phospholipid classes from the first dimension chromatography were subsequently analyzed in a second dimension system, a reversed phase HPLC (Dionex Ultimate ${ }^{\mathrm{TM}} 3000$ HPLC) coupled to a high resolution mass spectrometry equipped with a heated electrospray ionization probe. A C8 column $(1.0 \mathrm{~mm} \times 15 \mathrm{~cm}, 3 \mu \mathrm{m}$, Phenomenex, Inc.) was employed to separate non-oxidized and oxidized species. The temperature of column oven was maintained at $35^{\circ} \mathrm{C}$. The solvent system used for reversed phase HPLC was as follows: solvent A: acetonitrile/water/TEA/formic acid (90/10/0.5/0.5; v/v/v/v); solvent B: propanol/water/TEA/formic acid (90/10/0.5/0.5; v/v/v/v). The flow rate was 0.05 $\mathrm{mL} / \mathrm{min}$. The gradient was described below: 0-5 $\min , 50 \% \mathrm{~B} ; 5-15 \mathrm{~min} 50 \%-80 \% \mathrm{~B}$; $15-30$ min, $80 \%-100 \% B ; 30-35$ min, $100 \%-50 \% B ; 35-40$ min, 50\%B. Parameters for QEactive were as follows: spray voltage, $3.2 \mathrm{kV}$; negative mode; capillary temp, $320^{\circ} \mathrm{C}$; sheath gas, 8 units. Other tuning parameters were optimized for each individual lipid class. The QEactive was operated in data-dependent mode, with MS performed at 140,000 full width at half maximum (FWHM) resolution and MS/MS performed at 35,000 FWHM resolution. The five most abundant ions were selected for MS/MS. 


\section{LC-MS/MS Method for measuring monolyso-cardiolipins.}

Total lipid extraction corresponding to $1 \mu \mathrm{g}$ phosphorus was reconstitute in $20 \mu \mathrm{L}$ solvent A:B (1:9, v/v). Solvent A consisted of $n-p r o p a n o l / h e x a n e /$ water/0.5\% TEA/0.01\% Formic Acid (57/43/1/0.5/0.01; v/v/v/v/v) with 10mM ammonium acetate. Solvent B consisted of $n$-propanol/hexane/water/0.5\% TEA/0.01\% Formic Acid (57/43/8/0.5/0.01; v/v/v/v/v) with $10 \mathrm{mM}$ ammonium acetate. Total lipids were separated on a normal-phase column [Silica Luna $3 \mu \mathrm{m}, 150 \times 2 \mathrm{~mm}$, (Phenomenex, Torrance, CA)] with flow rate of $0.2 \mathrm{~mL} / \mathrm{min}$. The gradient is described below: 0-1 min, 10\%B; 1-15 min, 10\%-37\%B; $15-23 \mathrm{~min}, 37 \%-40 \% \mathrm{~B}$; 23-25min, 40\%-100\%B; 25-47 min, 100\%B; 47-48 min, 100\%-10\%B; $48-70$ min, 10\%B. Tetra-myristoyl cardiolipin (CL(14:0)4) (Avanti polar lipids, Alabaster, AL, USA) was used as an internal standard. Parameters for QEactive were as follows: spray voltage, $3.2 \mathrm{kV}$; negative mode; capillary temp, $320^{\circ} \mathrm{C}$; sheath gas, 8 units. Other tuning parameters were optimized for each individual lipid class. The QEactive was operated in data-dependent mode, with MS performed at 140,000 full width at half maximum (FWHM) resolution and MS/MS performed at 35,000 FWHM resolution. The five most abundant ions were selected for MS/MS.

\section{LC-MS/MS analysis for oxygenated species of TLCL}

Analysis of oxygenated species of TLCL was performed using a Dionex UltimateTM 3000 HPLC system coupled to a linear ion trap mass spectrometer (LXQ, ThermoFisher Scientific, San Jose, CA) using reverse phase column Luna C8 (2) $3 \mu \mathrm{m} 100 \AA 1 \times 150 \mathrm{~mm}$ (Phenomenex, Torrance, CA). A gradient of solvent A (acetonitrile: water: triethylamine: acetic acid, 45:5:0.25:0.25 v/v, in the 
presence of $0.01 \%$ formic acid) and B (2-propanol: water: triethylamine: acetic acid, 45:5:0.25:0.25, v/v, in the presence of $0.01 \%$ formic acid) was used at the flow rate of $60 \mu \mathrm{l} / \mathrm{min}$ as follows: $0-15 \mathrm{~min}$ isocratic at $35 \%$ solvent $\mathrm{B} ; 15-20 \mathrm{~min}$ linear gradient $35-85 \%$ solvent $B ; 20-25$ min isocratic at $85 \%$ solvent $B ; 25-28$ min linear gradient at $85-35 \%$ solvent $B ; 28-35$ min isocratic at $35 \%$ solvent $B$. Spectra were acquired in negative ion mode using a spray voltage of $5.0 \mathrm{kV}$ and a capillary temperature of $150{ }^{\circ} \mathrm{C}$.

\section{Evaluation of recovery of solid phase extraction}

Mixture of $\mathrm{PC}(16: 0 / 16: 0)$ and $\mathrm{CL}(18: 2)_{4}(0.5 \mu \mathrm{g}$ for each) were dissolved in loading solvent for SPE. After SPE, amount of phosphorus in each fraction was measured by phosphorous measurement using micro method ${ }^{2}$. The result shows that the recovery for $\mathrm{PC}$ and $\mathrm{CL}$ are $95.0 \%$ and $104.9 \%$, respectively.

Hydroperoxyl CL(18:2) ${ }_{4}$ was prepared and purified. Same amount of hydroperoxyl CL(18:2)4 before and after SPE pretreatment were analyzed by LCMS/MS. By comparing the peak area of hydroperoxide $\mathrm{CL}(18: 2)_{4}$ on base peak chromatogram, the recovery of hydroperoxyl CL(18:2)4 on SPE was $96.1 \%$. Meanwhile, no signal of hydroxyl-CL(18:2) 4 was detected.

Above result demonstrates SPE provides satisfying resolution and recovery, prevent hydroperoxyl CL being reduced into hydroxyl counterparts which may artificially increase the amount of hydroxyl products.

\section{Analysis of Gpx4 activity}


GPX4 activity of homogenates of MEF cells were monitored by disappearance of NADPH. Homogenates (300 $\mu \mathrm{g}$ of protein per sample) were incubated in buffer containing $0.1 \mathrm{M}$ Tris (pH8.0), $0.5 \mathrm{mM}$ EDTA, $1.25 \%$ triton $\mathrm{X}-100$ with $50 \mu \mathrm{M}$ of TLCLox. Concentration of NADPH was $0.2 \mathrm{mM}$, concentration of glutathione was $3 \mathrm{mM}$. Concentration of glutathione peroxidase was $1 \mathrm{u} / \mathrm{ml}$. 


\section{Reference}

1. Huang, Z., Jiang, J., Tyurin, V. A., Zhao, Q., Mnuskin, A., Ren, J., Belikova, N. A., Feng, W., Kurnikov, I. V., and Kagan, V. E. (2008) Cardiolipin deficiency leads to decreased cardiolipin peroxidation and increased resistance of cells to apoptosis, Free radical biology \& medicine $44,1935-1944$.

2. Böttcher, C. J. F., Van gent, C. M., and Pries, C. (1961) A rapid and sensitive submicro phosphorus determination, Analytica Chimica Acta 24, 203-204.

3. Tyurina YY, Tyurin VA, Kapralova VI, Wasserloos K, Mosher M, Epperly MW, et al. Oxidative lipidomics of gamma-radiation-induced lung injury: mass spectrometric characterization of cardiolipin and phosphatidylserine peroxidation. Radiat Res 2011, 175(5): 610-621.

4. Tyurina YY, Winnica DE, Kapralova VI, Kapralov AA, Tyurin VA, Kagan VE. LC/MS characterization of rotenone induced cardiolipin oxidation in human lymphocytes: implications for mitochondrial dysfunction associated with Parkinson's disease. Mol Nutr Food Res 2013, 57(8): 1410-1422.

5. Jiang J, Stoyanovsky DA, Belikova NA, Tyurina YY, Zhao Q, Tungekar MA, et al. A mitochondria-targeted triphenylphosphonium-conjugated nitroxide functions as a radioprotector/mitigator. Radiation research 2009, 172(6): 706-717.

6. Tyurina YY, Poloyac SM, Tyurin VA, Kapralov AA, Jiang J, Anthonymuthu TS, et al. A mitochondrial pathway for biosynthesis of lipid mediators. Nat Chem 2014, 6(6): 542-552.

7. Ji J, Tyurina YY, Tang M, Feng W, Stolz DB, Clark RS, et al. Mitochondrial injury after mechanical stretch of cortical neurons in vitro: biomarkers of apoptosis and selective peroxidation of anionic phospholipids. J Neurotrauma 2012, 29(5): 776-788.

8. Ji J, Kline AE, Amoscato A, Samhan-Arias AK, Sparvero LJ, Tyurin VA, et al. Lipidomics identifies cardiolipin oxidation as a mitochondrial target for redox therapy of brain injury. Nat Neurosci 2012, 15(10): 1407-1413.

9. Tyurina YY, Tyurin VA, Kaynar AM, Kapralova VI, Wasserloos K, Li J, et al. Oxidative lipidomics of hyperoxic acute lung injury: mass spectrometric characterization of cardiolipin and phosphatidylserine peroxidation. Am J Physiol Lung Cell Mol Physiol 2010, 299(1): L73-85.

10. Tyurina YY, Tungekar MA, Jung MY, Tyurin VA, Greenberger JS, Stoyanovsky DA, et al. Mitochondria targeting of non-peroxidizable triphenylphosphonium conjugated oleic acid protects mouse embryonic cells against apoptosis: role of cardiolipin remodeling. FEBS Lett 2012, 586(3): 235-241. 
11. Tyurina YY, Polimova AM, Maciel E, Tyurin VA, Kapralova VI, Winnica DE, et al. LC/MS analysis of cardiolipins in substantia nigra and plasma of rotenone-treated rats: Implication for mitochondrial dysfunction in Parkinson's disease. Free Radic Res 2015, 49(5): 681-691.

12. Tyurina YY, Tyurin VA, Epperly MW, Greenberger JS, Kagan VE. Oxidative lipidomics of gamma-irradiation-induced intestinal injury. Free Radic Biol Med 2008, 44(3): 299-314.

13. Tyurina YY, Kisin ER, Murray A, Tyurin VA, Kapralova VI, Sparvero LJ, et al. Global phospholipidomics analysis reveals selective pulmonary peroxidation profiles upon inhalation of single-walled carbon nanotubes. ACS Nano 2011, 5(9): 7342-7353.

14. Fernandez-Prada CM, Hoover DL, Tall BD, Venkatesan MM. Human monocytederived macrophages infected with virulent Shigella flexneri in vitro undergo a rapid cytolytic event similar to oncosis but not apoptosis. Infection and immunity 1997, 65(4): 1486-1496. 